\title{
حركة شباب المجاهلين واثرها في واقع الصومال السياسي
}

\section{أ. د منى حسيز عبيل}

\section{مركز الدراسات الاستراتيجية والدولية/جامعة بفداد}

\section{Muna 2205@yahoo.com}

DOI: https://doi.org/10.36473/ujhss.v60i4.1829

تاريخ الاستلام : 4021 / 1 /

تاريخ القبول : 15/ 2021 ( 202

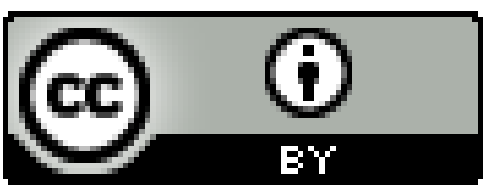

This work is licensed under a Creative Commons Attribution 4.0 International License

المستخلص

تعد حركة شباب المجاهدين من الحركات الاسلامية التي ظهرت في العام

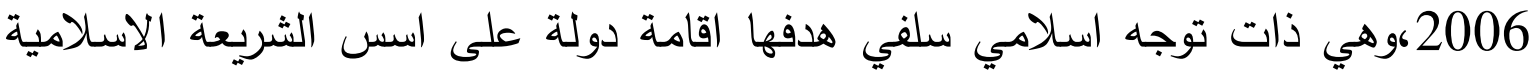

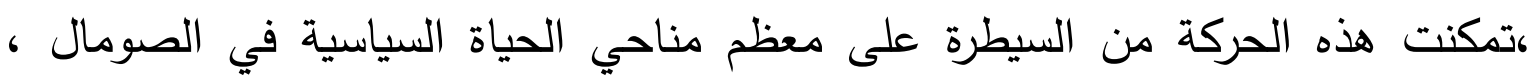

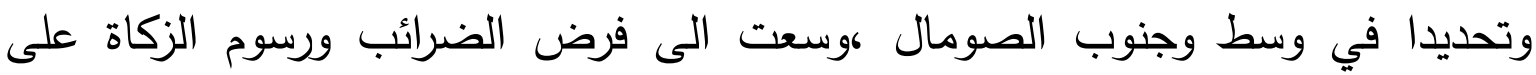

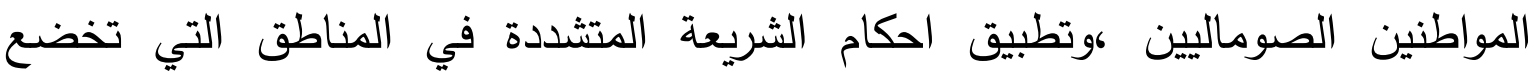

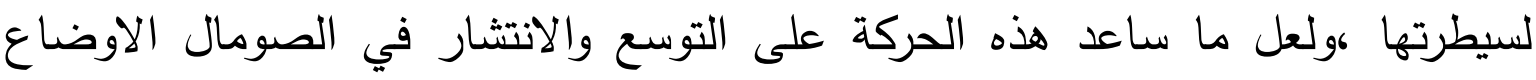

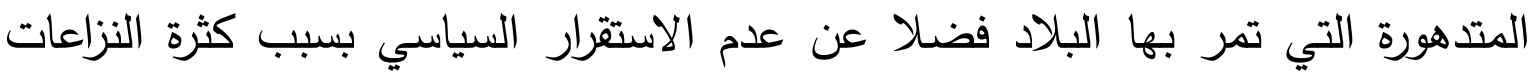

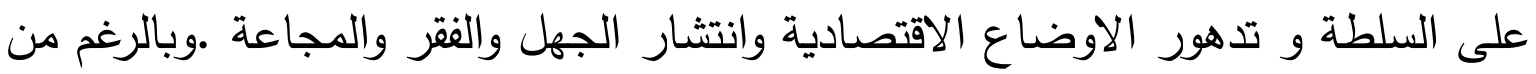

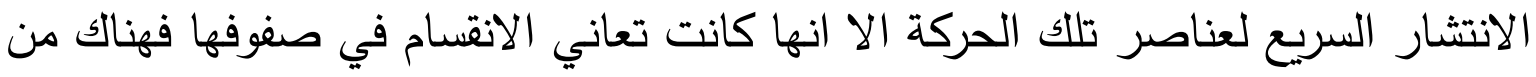

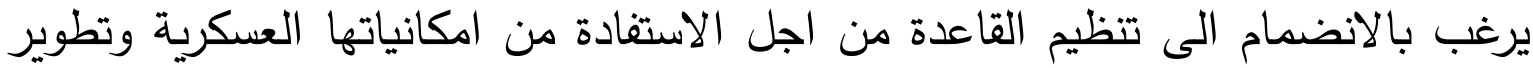

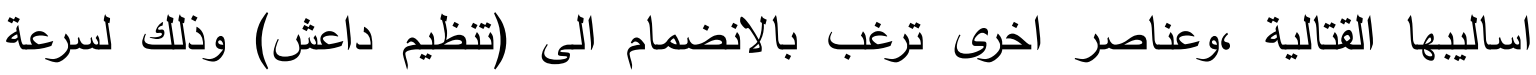

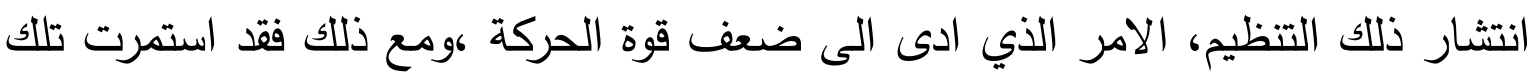

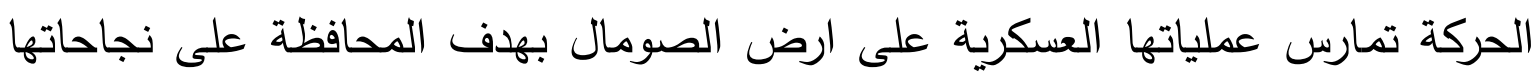
في الاستحواذ على مساحات شاسعة من البلاد.

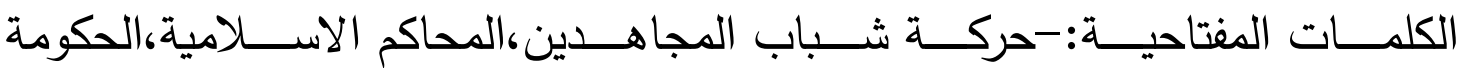
الصومالية،تظيم القاعدة،الثباب الجهادي،غياب الدولة الدياب. 


\title{
The Mujahideen Youth Movement and Its Impact on the Political Reality of Somalia
}

\section{Prof. Dr Muna Hussein Obaid \\ Center for Strategic and International Studies/University of Baghdad}

Muna_2205@yahoo.com

\begin{abstract}
The Young Mujahideen Movement is one of the Islamic movements that appeared in 2006, and it has a Salafi Islamist orientation that aims to establish a state on the basis of Islamic law. This movement managed to control most aspects of political life in Somalia, specifically in central and southern Somalia, and sought to impose taxes and fees. Zakat on Somali citizens, and the application of strict Sharia provisions in the areas under its control, and perhaps what helped this movement to expand and spread in Somalia is the deteriorating conditions the country is going through, as well as political instability due to the many conflicts over power, deteriorating economic conditions, the spread of ignorance, poverty and famine. Despite the rapid spread of the elements of that movement, it was suffering from a split in its ranks, there are those who wish to join the Al-Qaeda organization in order to benefit from its military capabilities and develop its combat methods, and other elements want to join (ISIS) due to the rapid spread of that organization, which led to the weakness of the movement's strength, however, that movement continued to exercise its military operations in Somaliland in order to maintain its successes in the acquisition of large areas of the country.
\end{abstract}

Keywords: - The Mujahideen Youth Movement, Islamic Courts, the Somali government, Al-Qaeda, Al-Shabaab Jihad, the absence of the state

تعد الصومال من البلدان الافريقية الواقعة شرق القارة الافريقية، عانى هذا البلد شانه

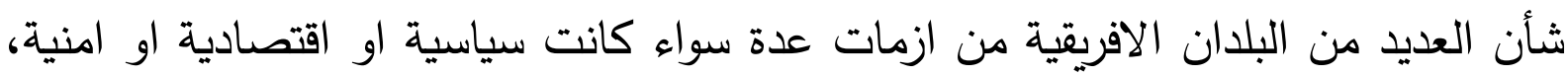
دفعتها لان تكون من افقر البلدان في القارة الافريقية بسبب حالة النهب والسلب وفساد الحكومات التي تعاقبت على حكم الصومال ،فضلا عن تعرضها لعملية التقسيم من قبل 
الاستعمار الاوروبي، والذي منح دولا عدة الحق في ادارة اجزاء معينة من ارض الصومال ومنها بريطانيا وايطاليا وفرنسا. وبالرغم من استقلال الصومال في العام 1960 ، ومحاولة الحكومة الصومالية توحيد شطري البلاد الا ان الحكومة الصومالية تعرضت لانقلاب عسكري قاده سياد بري في العام 1969.والذي لم يكن حكمه افضل من سابقه فقد تدهورت الاوضاع السياسية في الصومال فضلا عن دخولها في حرب مع اثيوبيا في العام 1977الى جانب ذلك فقد كان لسياسته

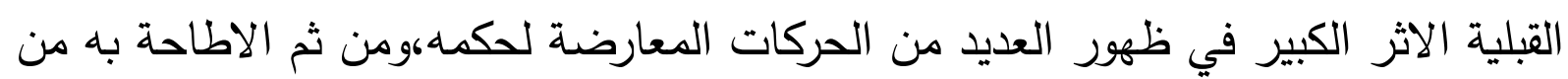

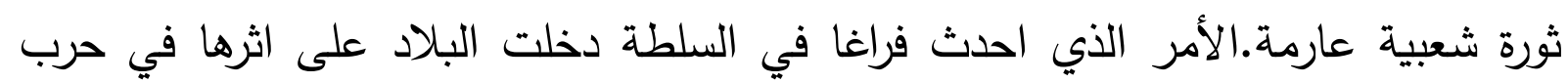
أهلية ، كان لها الاثر الكبير في بروز العديد من الحركات السياسية في الصومال ولاسيما الإسلامية منها والتي ظهرت في بادئ الأمر على شكل محاكم وهيئات اتحدت فيما بئهي فينها لتشكل المحاكم الإسلامية. فضلا عن ذلك ، فقد شهدت الساحة الصومالية ظهور أحزاب إسلامية أخرى كان لها

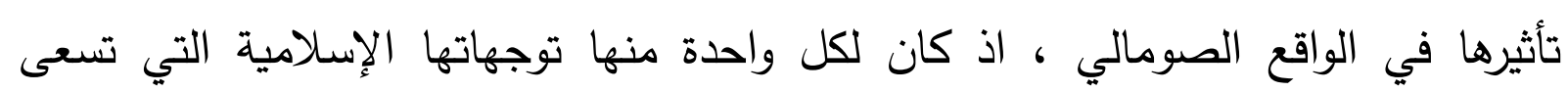

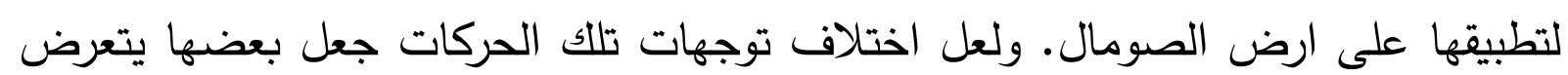

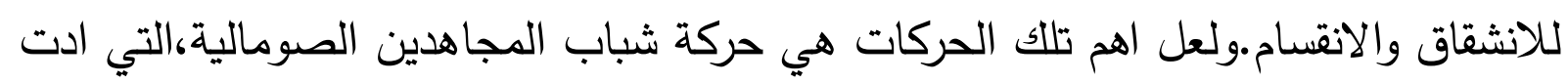
دور كبير في الحياة السياسية الصومالية وذلك من خلال سرعة انتشارها وفرض سيطرتها على اجزاء واسعة من الصومال وتحديدا في وسط وجنوب الصومال،فضلا عن خوضها ونها ونها العديد من المعارك مع الفرق العسكرية الحكومية.ولاهمية حركة شباب المجاهدين فقط تم وناء

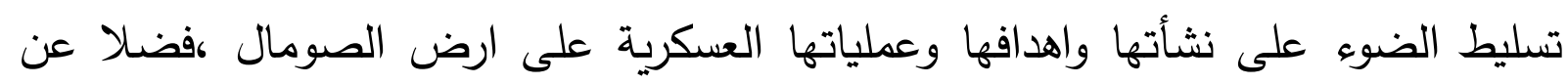
انتشارها السريع في العديد من المناطق الصومالية وتهدف الدراسة الى رصد وتحليل طبيعة حركة شباب المجاهدين ، وما قامت به تجاه ابناء الشعب الصومالي وتوضيح طبيعة أدوارها السياسية على ارض الصفية الصومال.

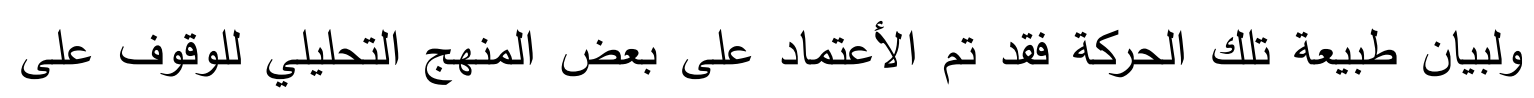

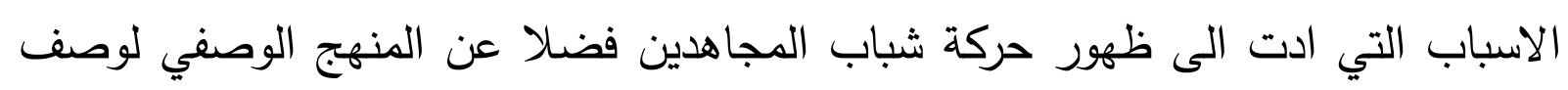
طبيعة علاقة حركة شباب المجاهدين بالحكومة الصومالية. 


$$
\text { اولا:-عوامل ظهور حركة شباب المجاهدين: }
$$

أسهمت مجموعة من العوامل، ادت الى ظهور حركة شباب المجاهدين، ولعل اهمها:-

$$
\text { 1-تدهور الاوضاع السياسية في الصومال }
$$

يعد الصومال بلد مترامي الاطراف ،تبلغ مساحته حوالي 600 الف كم مربع،ويمتلك اكبر ساحل على المحيط الهندي.وتعد السيطرة على الصومال سيطرة على ددخل البحر الاحمر وخليج عدن ومداخل الخليج العربي وصولا الى باب المندب،اي ان شرايين النفط

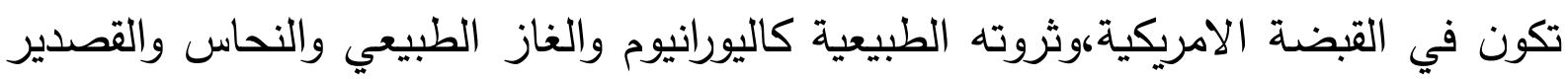
والملح والثروة الحيوانية الهائلة.اما الطابع المميز لهذا البلد الذي انضم الى المجموعة العربية من خلال جامعة الدول العربية ،اعتماد اقتصاده على تربية وتصدير الماشية .فليس غربيا ان تعني كلمة الصومال باللغة المحلية (اذهب واحلب).ولكون اقتصاده ضعيفا فان اجمال

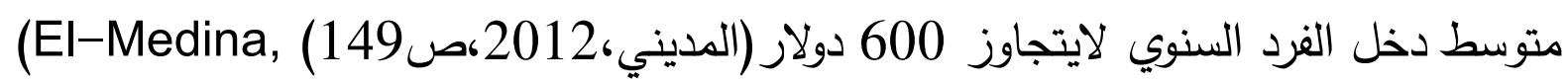

$$
\text { 2012, p. 149)). }
$$

وبالعودة الى تاريخ الصومال والاوضاع التي ادت الى ضياع ذللك البلد ،كانت الاراضي الصومالية منذ القرن التاسع عشر وحتى استقلال الصومال في تموز من العام 1960 ترزح الاحتلال الاثيوبي وسيطرة الدول الاستعمارية الاوربية اذ مرت عملية تقسيم الصومال بمرحلتين رئيسيتين تمت الاولى في بداية ستينيات القرن الماضي ،واستكملت الثانية في

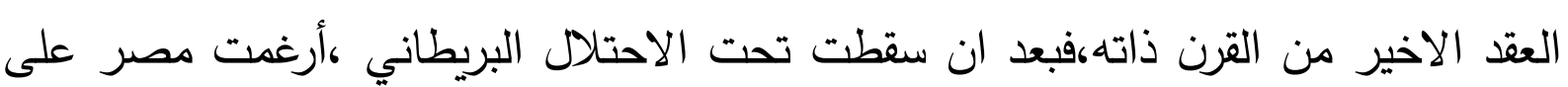
التخلي عن وجودها في الصومال الذي كان جزءا من الدولة الدصرية حتى عام 1884،وذلك قبل ان تسارع بريطانيا الى اقامة ما عرف بالصومال البريطاني في العام 1887.وكانت فرنسا قد اخذت قبل ذلك بثلاثة اعوام ما عرف بالصومال الفرنسي ، بالتوازي

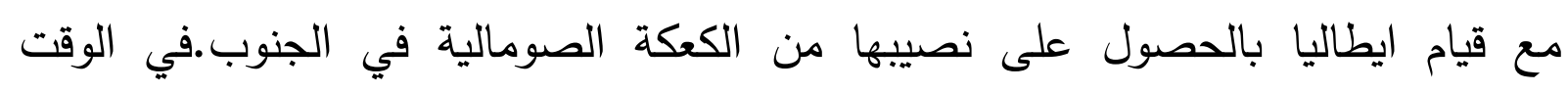
ذاته،منحت الدول الاوربية الثلاث الحق لاثثيوبيا في السيطرة على الصومال الغربي(اوغادين)

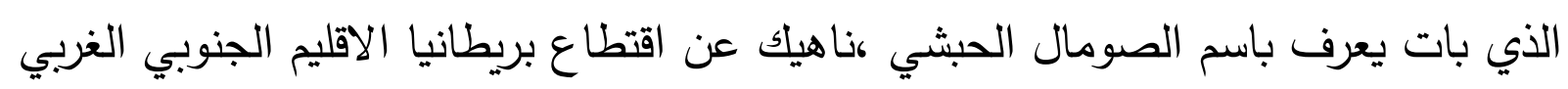

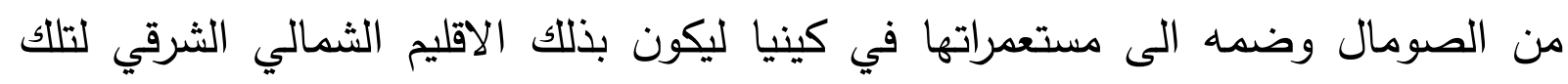

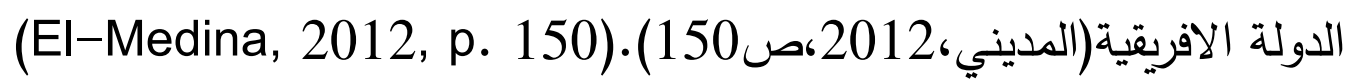


عانى الصومال حاله كحال الدول الافريقية التي خضعت للاستعمار والسيطرة الاجنبية،من التخلف السياسي والاقتصادي والاجتماعي ،وعانت شعوبه من الفقر والعوز ،ولقيت حركات تحريره ضربات متلاحقة لاجهاضها ،الا ان استتهاض حركات التحرر في القارة الافريقية والعالم الثالث كانت متوقدة،واخذت في عقد الخمسينيات من القرن العشرين تصعد وتستتهض مستلهمة النموذج الخاص بتكوين دولة وطنية قومية ،وكان يراودهم حلم الاستقلال السياسي والاقتصادي ،وحلم تذويب التكوينات القبلية والعرقية في اطار قومي شامل يقبل بحق الجميع في التواجد والمشاركة السياسية والاقتصادية واحترام الخصوصيات العرقية والدينية دون ان ينقصهما،ولكن كانت هناك مشكلة الحدود التي خلقها

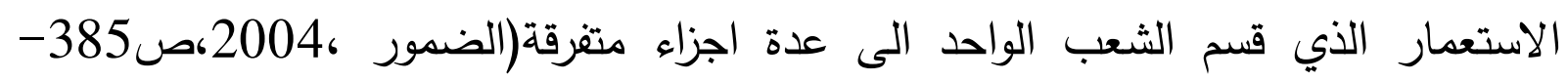

(Aldhmoor, 2004, pp. 385-386).(386

وبقي الثعب الصومالي موحدا ثقافيا بالرغم من التجزئة الاستعمارية .فكان الاستقلال

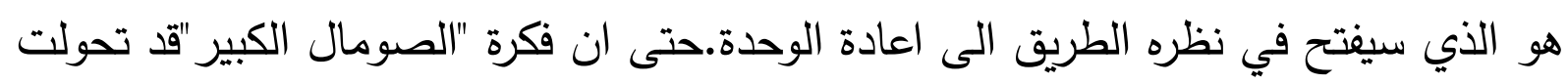
مشروعا وطنيا مركزيا افضى الى توحيد المستعمرتين تحت سلطة اول حكومة صومالية حرة

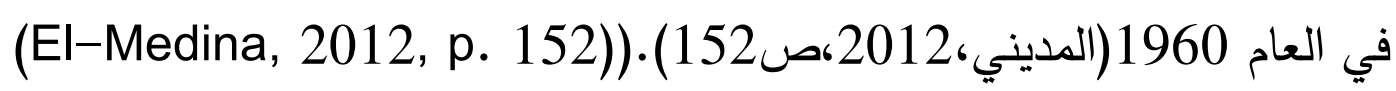
بعد توحيد شطري الصومال الشمالي والجنوبي في العام 1960 ،بدأت مرحلة تثبيت

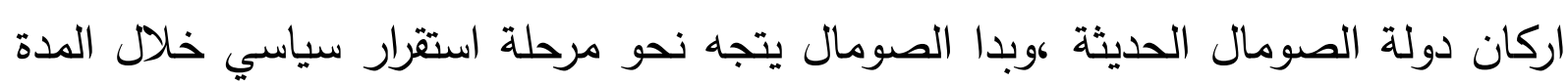

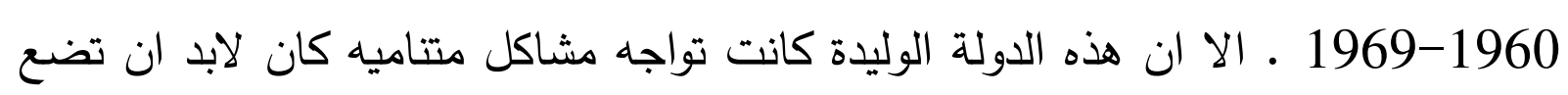

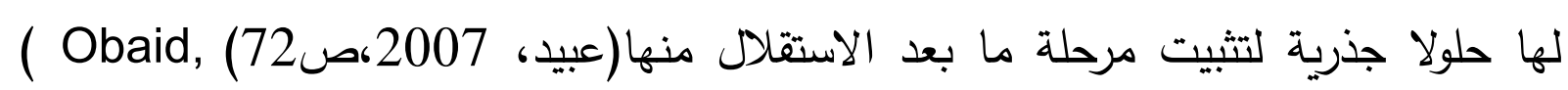
2007, p.72):-

1- الحفاظ على وحدة البلاد باعتماد اجراءات تضمن تماسكه

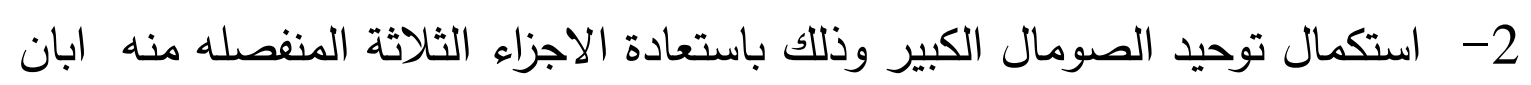
مرحلة الاستعمار 3- مشكلة اللغة ،اذ لم تكن ثمة لغة صومالية مستقلة ومحددة. 
4- الركود الاقتصادي الذي كان متفاقما انذاك بسبب ضعف السياسات الحكومية في

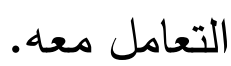

لذا فقد سعى النظام السياسي لدولة الصومال الكبرى للم شمل الصوماليين الموزعين على الدول المجاورة الا ان ذلك ادى الى دخول البلاد في حرب مع اثيوبيا عام 1964 • على اقليم اوغادين جرت في السنة ذاتها اول انتخابات في الصومال الى تشكيل اول حكومة برئاسة عبد الرشيد ماركي(1) ،غير ان حكومته لم تستمر مدة طويلة بسبب اتهامها بالفساد وسوء الادارة الامر الذي ادى الى تعرضها لانقلاب عسكري قاده الملازم محمد سياد بري في لاب العام

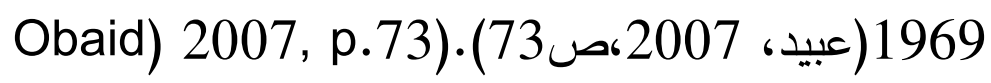
2-حكومة الرئيس سياد بري في الصومال

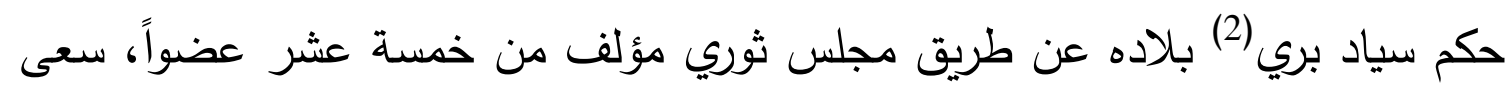
من خلاله الى حل البرلمان ،ووقف العمل بالدستور، وحل الاحزاب السياسية ، وادخاله تعديلاً على اسم البلاد عام 1970اذ أصبح يعرف باسم (جمهورية الصومال الديمقراطية)(

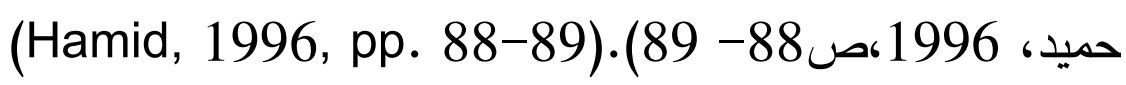
اتبع سياد بري عام 1976 نظام الحزب الواحد ، فأسس الحزب الاشتراكي الثوري

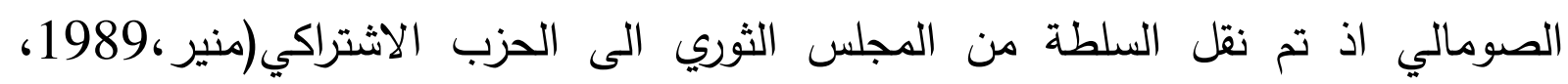

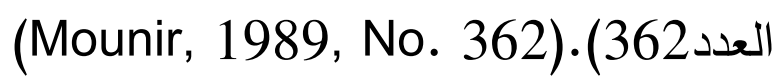

كما تبنى النهج الاشتراكي كنظام للحكم في محاولة منه للتقرب من الاتحاد السوفيتي، وأتخذ مجموعة من الاجراءات منها تأميم المصالح والبنوك الاجنبية والتي أسهمت في زيادة التهني شعبية نظام سياد بري .اذ ساهم ذلك الاجراء في ارتداء النظام مظهراً وطنياً في مواجهة

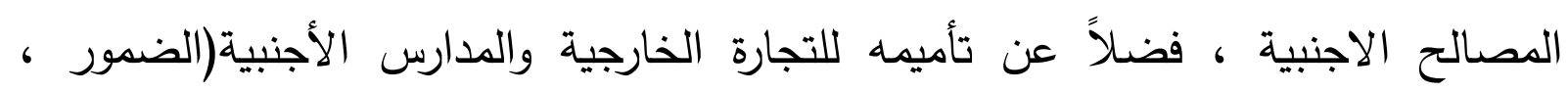
(Aldhmoor, 2004, p.404))..(404 2004 1الا انه وبمرور الوقت اتضح ان بري - كرجل عسكري- يصعب عليه الاعتماد على المؤسسات الديمقراطية او التعامل مع المفكرين - وبالتالي فقد زاد اعتماده على رجال الأمن، 
وتقييده لحرية التعبير مما ادى الى فقد العديد من القوى التقدمية والديمقراطية حماسهم للنظام ومن ثم تناقص شعبيته(الضمور ، 2004 ، ص205). (Aldhmoor, 2004, p405) ونتيجة لإخفاق النظام على صعيد الجبهة الداخلية وصعوبة موقفه على المستوى

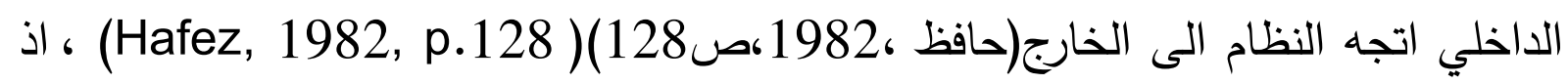
حاول تهدئة الاوضاع على الحدود مع كل من اثيوبيا وكينيا، بالطرق الدبلوماسية والسياسية، ولكن محاولاته تلك فثلت بسبب عمق التباين في المواقف. وعلى اثر ذلك حدث نزاع مسلح بين الصومال واثيوبيا حول اقليم اوغادين في تموز 1977، نجحت الصومال في ولي الصني

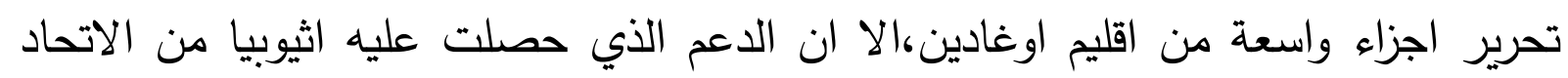

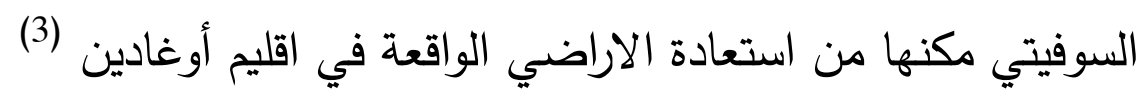
ونتيجة لتغير الموقف السوفياتي من نظام سياد بري اتجه عام 1978 نحو الولايات

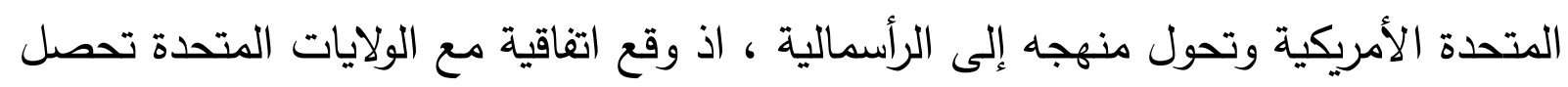

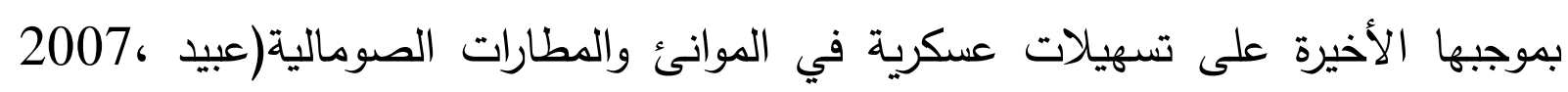

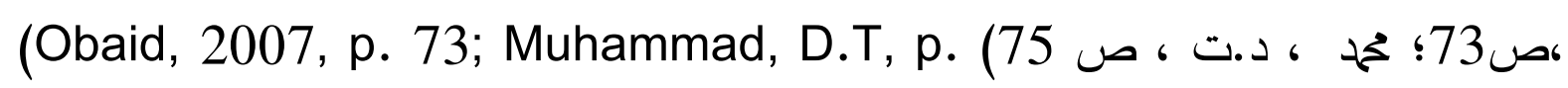

أدى تفاقم الأحداث على الصعيدين الداخلي والخارجي على حد سواء الى وضع سياد بري دستوراً جديداً للبلاد عام 1979 ركز فيه سلطات الدولة بيد رئيس الجمهورية ، كما

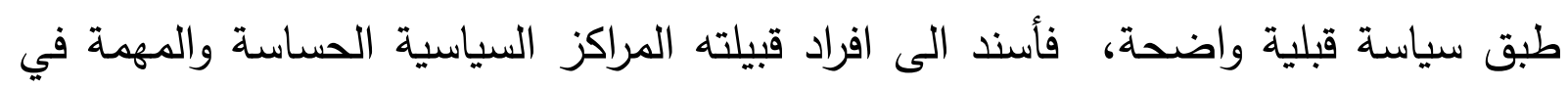
البلاد.ثم ضيق تلك الدائرة تدريجيا حتى انحصرت الامتيازات السياسية في افراد

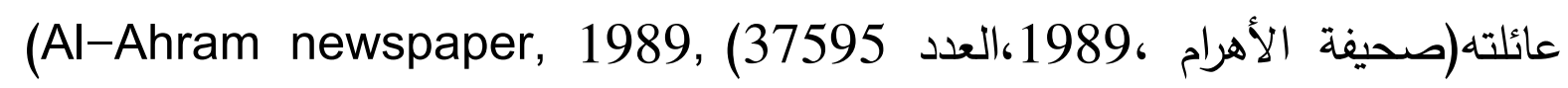
37595 issue

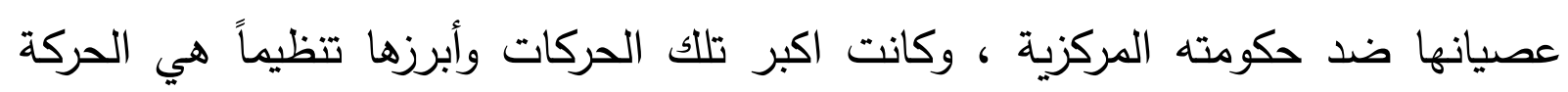
القومية الصومالية التي تأسست عام 1980 بزعامة عبد الرحمن علي احمد الملب بـ(تور)(

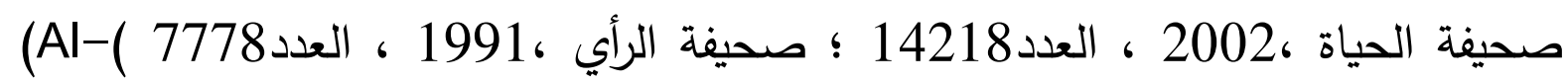
Hayat Newspaper, 2002, No. 14218; Al-Rai Newspaper, 1991, No.

7778). 


$$
\text { 3-غياب الدولة في الصومال }
$$

يمثل الصومال حاله فريدة من نوعها في العالم حيث يعيش ماساة حقيقية بكل المقاييس فالحرب الاهليه تقتك به منذ اكثر من عقدين من الزمان في ظل انهيار الدولة وغياب حكومة مركزية تسيطر على البلاد بعد الاطاحة بنظام الرئيس سياد بري من خلال ثوره

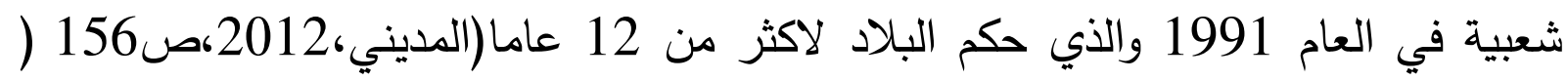
(El-Medina, 2012, p. 156). بعد سقوط نظام سياد بري وتولى علي مهدي السلطه عام 1991(محمود ، 1990،ص 22) برزت الخلافات بين فصائل الحركة القومية الصومالية اذ ان حمح فرح عيديد رئيس المؤتمر الصومالي الموحد ظل رافضا ومنافسا لعلي مهدي وعكس هذا الخلاف رغبة واضحة في الاستئثار بالسلطة من جانب الطرفين مما ادى من ناحية اخرى الى اثاره مخاوف قبائل الاسحق التي تعيش في شمال الصومال واتجهت لهذا السبب نحو الانفصال

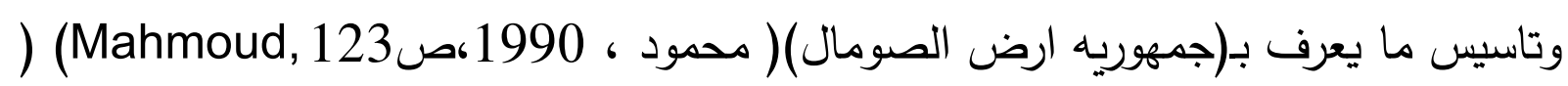
تهكات 123. p تحكمها مجموعة من القبائل اضفى كل منها. على نفسه اسما حزبيا جمع تحت لوائه ابناء

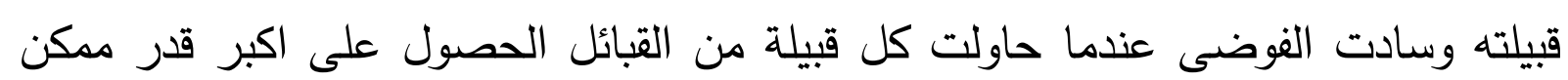

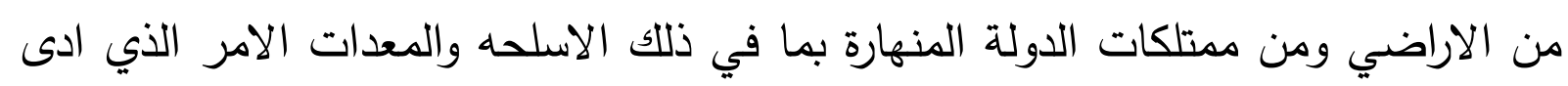
من الناحية العملية وقتذاك الى نشوء عدد من الدويلات او الاقطاعيات المنفصلة والمتنافسة في الصومال حيث فرضت قبيلة الدارود سيطرتها على جنوب الصومال بينما اعلنت الجبهة

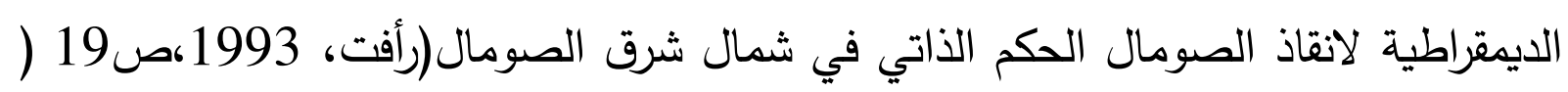

(Raafat, 1993, p.19).

لقد كان من نتيجه تلك المنافسات ان دخلت الصومال في ازمة حادة سببتها عوامل عدة منها طبيعة الصراع العرقي والقبلي الصومالي وتفاقم الازمة الاقتصادية ،وازدياد الديون الخارجية ،التخلف السياسي المتمثل في سيطرة الزعيم او جماعته على مقاليد السلطة

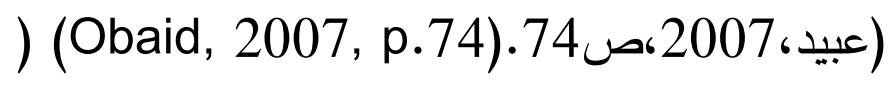


ومنذ انهيار مؤسسات الدولة في الصومال عام 1991 اصبحت البلاد بلا حكومة

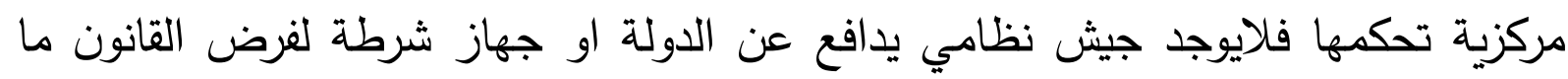

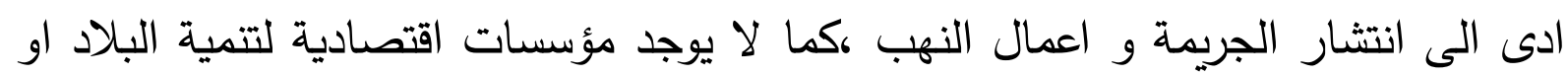

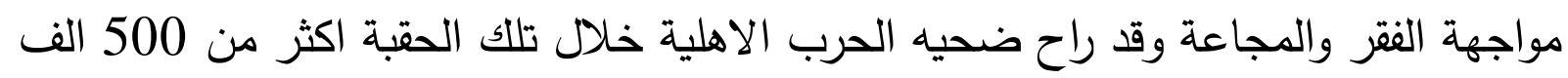
شخص فضلا عن اكثر من مليون لاجئ صومالي في الدول المجاورة و في العالم كافة(المديني،2012،صاعنا، El-Medina, 2012, p156) ( (. 156) ويعيش السكان اوضاع معيشية قاسية وقد شهدت الفترة الماضية وعلى مدى عقدين ثلاث عشرة محاولة لتتصيب حكومة وبرلمان من خلال جولات المفاوضات المتعددة في مصر وليبيا وجيبوتي مكيه واثيوبيا وكينيا لكن هذه الحكومات كانت على الورق فقط وانهارت جميعها نتيجه للتنازع بين الفصائل الصومالية على السلطة وتشابك دور الاطراف الخارجية لاسيما اثيوبيا. التي

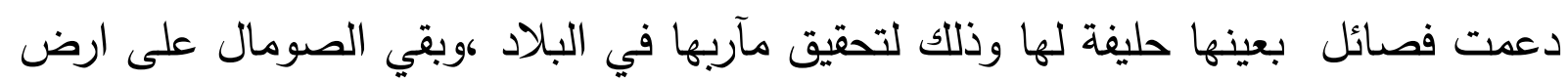

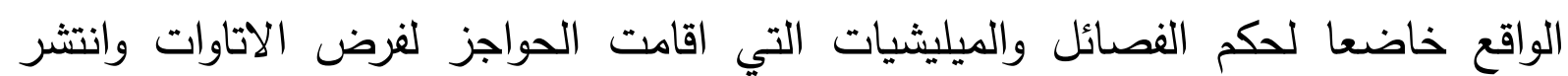
مقاتلوها في المناطق التي تسيطر عليها لاسيما العاصمة مقديشو فضلا عن ذلك شهدت تلكك الفترة استقلال جمهورية ارض الصومال وجمهورية بلاد بونت.وقد شهدت جهود الدصالحة تطورا ايجابيا فبعد 41 جولة من محادثات السلام التي استضافتها كينيا وبرعاية الاتحاد الافريقي وقع السياسيون وقادة الحرب الرئيسيون في البلاد في 29 يناير/ كانون الثاني 2014 على اتفاق سلام يقضي باقامة برلمان وطني جديد يقوم بدورة بانتخاب رئيس

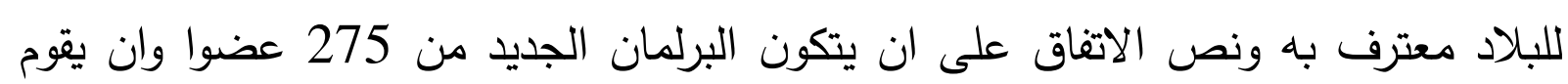

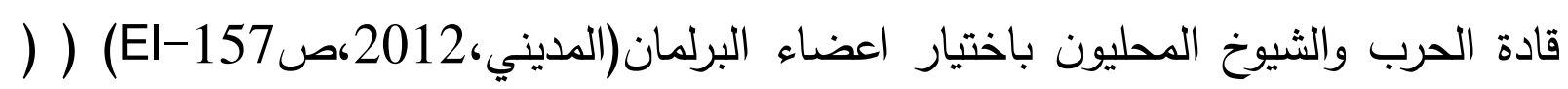
ني Medina, 2012, p نتخب بالاجماع عبد الله يوسف رئيسا للبلاد،وعلى الرغم من تشكيل تللك الحكومة الا انها لم لم المادئ

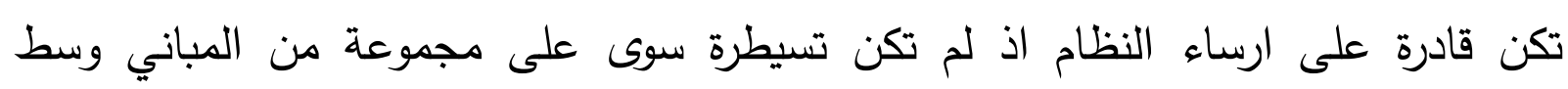
العاصمة مقديشو،اذ كانت تواجه تلك الحكومة تمرد المحاكم الاسلامية حينذاك والين تمكنوا

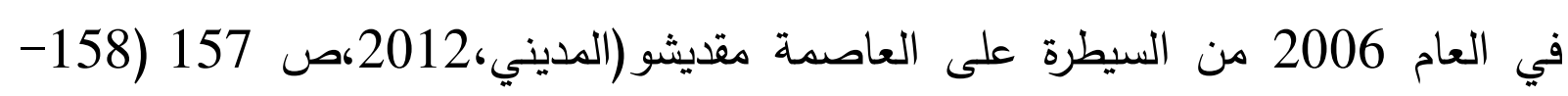
(El-Medina, 2012, p. 157-158). 


\section{ثانيا:-ظهور حركة شباب المجاهدين في الصومال

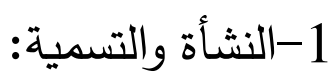

جاء ظهور حركة شباب المجاهدين كنتاج لحالة التفكك الذي شهدته المحاكم الاسلامية، اذ خرجت بعض القيادات الثبابية عام 2004 ليعلنوا انشقاقهم عن المحاكم الاسلامية وأسسوا حركتهم الخاصة التي سميت بـ(شباب المجاهدين) وحددوا أهدافها في مقاومة القوات الاثيوبية وقوات حفظ السلام التابعة للاتحاد الافريقي ، فضلاً عن مقاومتهم للقوات الموالية

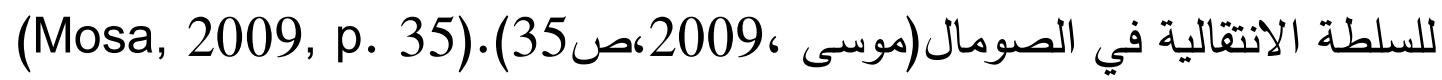
ويمكن إرجاع سبب الانشقاق عن المحاكم الاسلامية لرفض حركة شباب المجاهدين

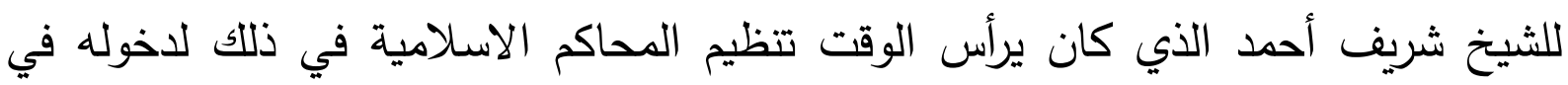
مفاوضات سلام مع الحكومة الصومالية برعاية الامم المتحدة ، اذ عارضت حركة شباب المجاهدين ذلك وعدته خيانه لمبادئها الجهادية ـ فضلا عن رفض حركة شباب المجاهدين الانضمام الى التحالف الذي شكله الثيخ شريف أحمد والذي عرف بـ(التحالف من اجل

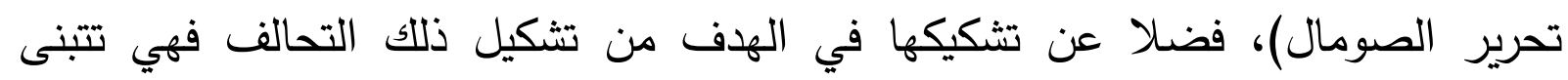
خطاباً اسلامياً اكثر تشدداً من المحاكم الاسلامية ، كما عرف عنها توجهها السلفي

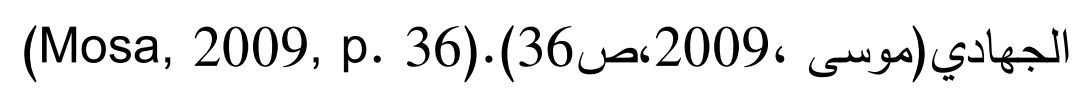
ويرى البعض ان خلافات تلك الحركة مع بقية الفصائل الاسلامية الصومالية تتجاوز

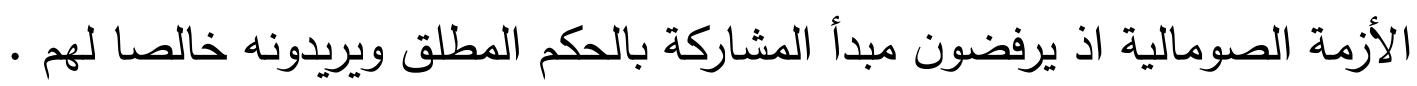

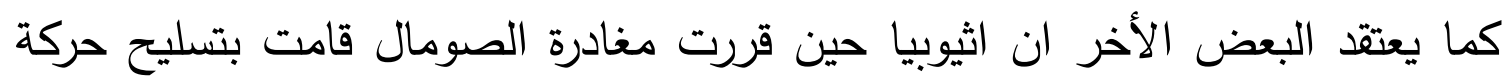
الثباب وزيادة نفوذهم بطريقة غير مباشرة ، وقد يتبادر الى الذهن ما الفائدة التي تجنيها

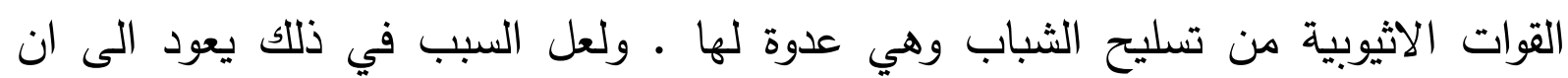
الحكومة الاثيوبية ارادت ان تستمر حالة عدم الاستقرار في الصومال بعد خروجها ، لاسيما

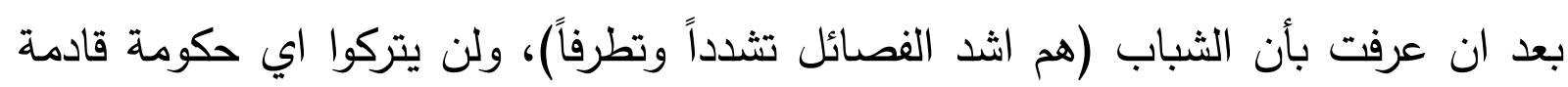

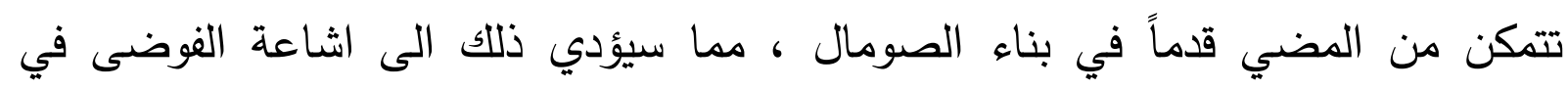
الصومال من جديد ، الامر الذي قد يسمح للحكومة الاثيوبية بالتدخل في الثأن الصومالي 
) (Somali Reality www.aljazeera.net.p6،2010 مرة أخرى(الواقع الصومالي 2010, www.aljazeera.net.p6). تمثل حركة شباب المجاهدين بفكرها المتطرف اكبر عقبة امام الحكومة الصومالية

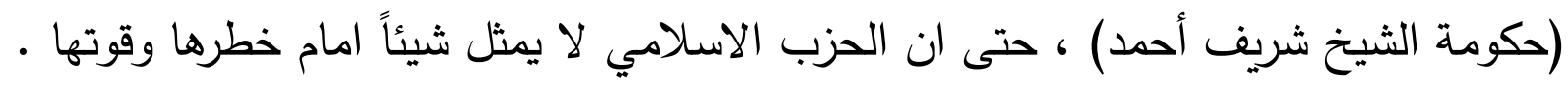

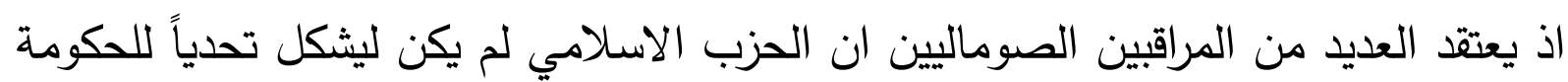

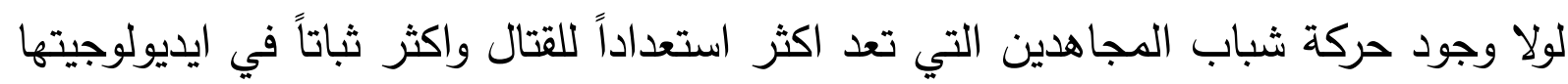

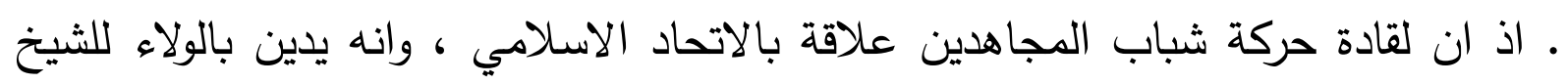

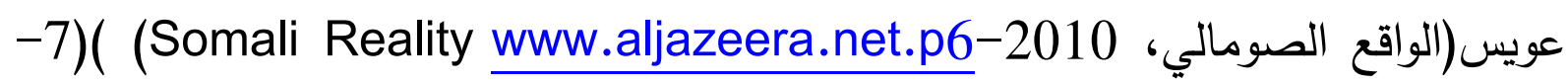
2010, www.aljazeera.net.p6.

وحركه شباب المجاهدين أو حركة الشباب الصومالية أو الثباب أو المجاهدين أو حركة

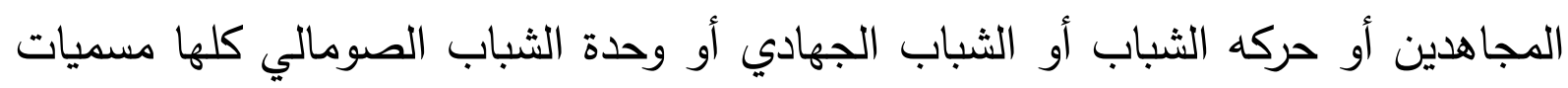

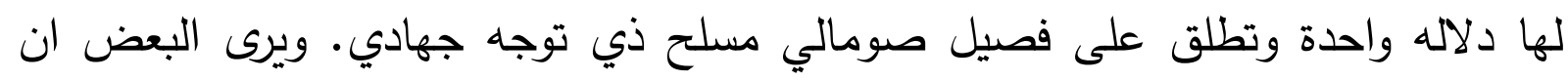

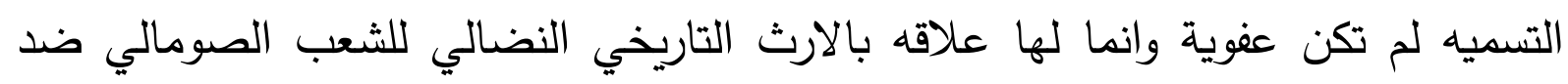
الاستعمار الاوروبي والاثيوبي الذي لم يكتفي باحتلال الصومال وانما مزق كيانه الى خمسه

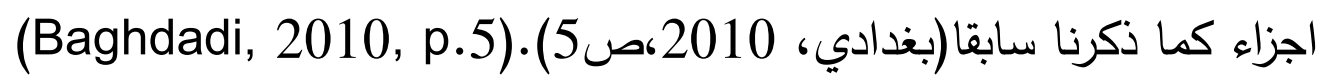
فبمقدار ما تدل تسمية حركه شباب المجاهدين على متغيرين اساسيين هما (الثباب)

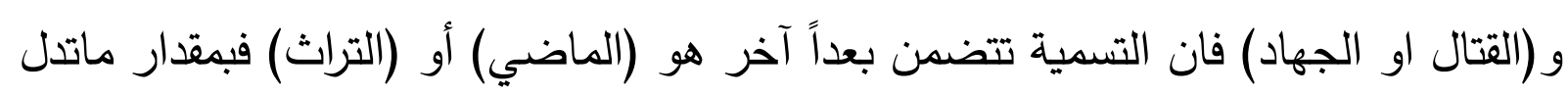
التسمية على الثباب صغار السن الذين يمثلون اغلبية اعضاء الحركة فان التسمية ارتكنت

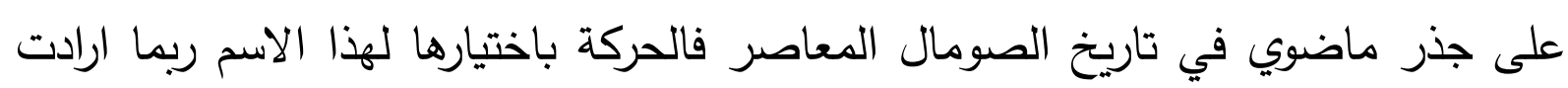

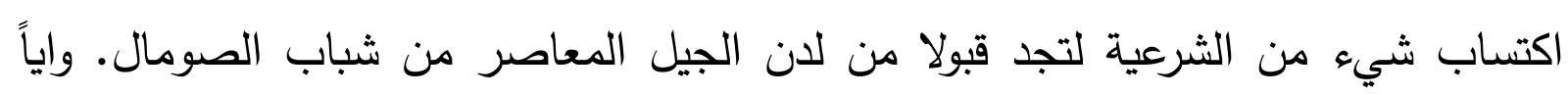
كان الامر فان تسمية (الشباب) اصبحت دالة هذابل هذا التنظيم (الشباب) عمرا وعنوانا

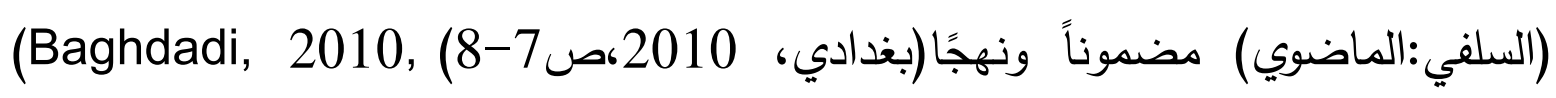
p. 7-8). 
2-اهداف حركة الشباب:

تسعى حركة الشباب حسب ما يفهم من ادبياتها الى تحقيق عدة اهداف ابرزها(احمد،

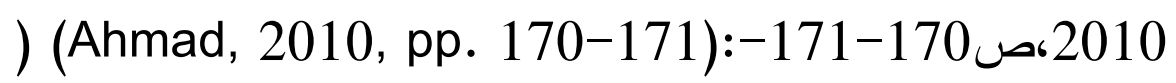

1-اقامة الامارة الاسلامية في الصومال وهذا يمثل بالنسبة إلى السلفية الجهادية أحد ابرز اهدافها وذللك لاسقاط وتغيير انظمة الحكم القائمة ليس في الصومال فحسب إسب بل في دول العالم الاسلامي عبر نشر العنف واحداث ثورات دموية وانقلابات عسكرية على مستوى الدولة أو السلطة وعلى مستوى المجتمع. 2- تطبيق الشريعة الاسلامية على فهم و منهج السلفية الجهادية ويتركز نشاط الحركة في مجال تطبيق الشربعة لاسيما في جوانب العقوبات والجنايات ولا تولي الاهتمام الكافي لجوانب العدالة الاجتماعية والاقتصادية والسياسية للمجتمع، رغم محاولات لهات جيش الحسبة لتقديم بعض الخدمات الاجتماعية والاقتصادية للشعب الصومالي

$$
\text { كتوزيع الراكوات وغيرها. }
$$

3- استمرار ومواصلة عمليات العنف العسكري الجهادي حتى تحقيق النصر أو الموت من أجلها (النكاية بالعدو أو نيل الشهادة) ولتحقيق هذا الهدف فتحت الحركة معسكرات لأعداد وتأهيل وتدريب المقاتلين من جميع اجزاء الصومال وخارجها و يدخل ضمن نطاق ودائرة الاعداء كل من -الدول والحكومات والمنظمات والمجموعات التي تعترف بالشرعية الدولية والاقليمية و تلتزم بالقواعد والقوانين الدولية . -التراث الصوفي والتقليدي الذي يشكل الاغلبية الصامتة في عموم افريقيا و في الصومال خاصة وذللك لتغيير جميع الملامح والاماكن التي يقدسها اتباع الطرق لاتئي الصوفية.وقد اتخذت الحركة بعض الاجراءات الاستئصالية للاشخاص والاشياء التي لها علاقة بهذا التقليد والتراث مثل هدم الاضرحة ونبش القبور واستخراج الرفات واخذها الى اماكن غير معلومة.ومنع الاحتفال بالمولد النبوي وغيرها. وقد تم تحطيم البنى التقليدية الثقافية منها والاجتماعية للمجتمع الصومالي عبر استخدام أدوات القسر والاكراه ووسائل العنف العسكري والارهاب الفكري من نشر الخوف 
والرعب في نفوس مخالفيهم سواء في الفهم الديني او في المناهج العقلية والاجتهادية حتى يتسنى للحركة اعادة صياغة المجتمع الصومالي من جديد.

ويرى بعض الباحثين ان منطلقات الحركة تتلخص في )احمد، 2010،صدئ

(Ahmad, 2010, p. 172):

1- رفض الافكار والمبادئ العلمانية التي انتجتها الحضارة المادية بشقيها الغربي (الديمقراطية في الحكم والليبرالية في المجتمع والاخلاق والراسمالية في الاقتصاد) او الشرقي (الاشتراكية والثيوعية) واعتبار المؤسسات والانظمة والافكار التي وائ تنبثق عنها مؤسسات كفر والحاد.

2- اعتبار الحكومات والنظم السياسية القائمة انظمة كفر تخالف الاسلام وتعادي الشريعة الاسلامية وتوالي اعداء الدين الاسلامي. ويعد العنف الوسيلة الوحيدة

الناجعة لاحداث تغييرات جوهرية في بنية النظم السياسية والاجتماعية والثقافية 3- رفض التعامل مع مؤسسات الدولة على اعتبار ان ذلك سيؤدي الى اعتراف وتقوية مؤسسات الكفر والجماعات الممتنعة عن تطبيق الشريعة والتترس خلف هذه الجماعات الكافرة التي لا يجوز لآحاد المسلمين وغيرهم ان يتعاملوا معها على ولى لهيق اساس قاعدة الولاء والبراء في الاسلام ع-عدم الاعتراف بمفاهيم الوطن والمواطن باعتبارها قيما ترسخ الافكار والمبادئ

العلمانية. 3-مصادر تمويل الحركة:

تعددت مصادر تمويل حركة شباب المجاهدين الصومالية ،اذ كانت الحركة تحصل على دعمها من مصادر متعددة ومنها قيام عدد من الصوماليين بتحويل العملات لها من لهن الخارج وعبر دول مختلفة. فضلا عن ذلك فان الحركة كانت تمارس التجارة من خلال ميناء كيسمايو الصومالي وكان من ابرز ما تتاجر به الحركة او بالاحرى تعمل على تهريبة هو

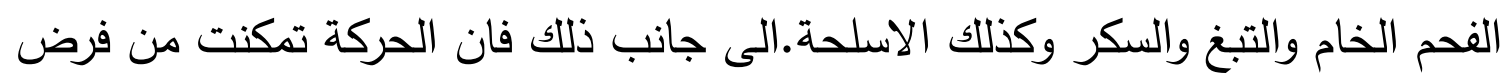
القوانين وجباية الزكاة من المواطنين وتحديدا بعد ان تمكنت من فرض سيطرتها على مناطق 
وسط وجنوب الصومال ،كما استطاعت الحركة من فرض الضرائب على ميناء مقديشو ،وتعد تلك الضرائب من اهم مصادر تمويل دخل حركة شباب المجاهدين

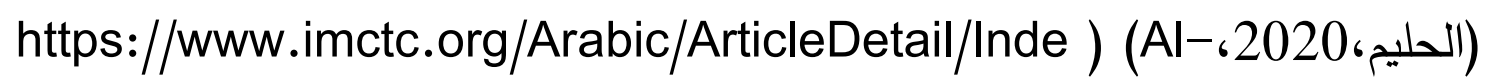
Halim, 2020, https://www.imctc.org/Arabic/ArticleDetail/Inde)..

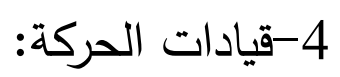
لا يعرف الكثير عن قيادات تلك الحركة ، اذ ان هناك من يعتقد ان لـه قياداته الخاصـة

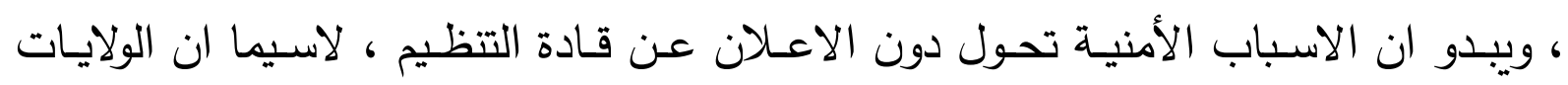
المتحدة الامريكية اشـارت ضمن تقريرها السنوي حول مـا يسمى بـ(الارهاب لعام 2007)، 2008 ن ف نذي والـ https://www.imctc.org/Arabic/ArticleDetail/Inde ） (الحليم،2020) (Halim, 2020, https://www.imctc.org/Arabic/ArticleDetail/Inde الجماعـة راديكاليـة متطرفـة ، وانها تمثل تهديداً الاكثر خطورة للولايـات المتحدة الامريكية ومصالحها في المنطقة ، وان بعض افرادها - وفقا للتقرير - ينتمون للقاعدة ، وانهم تدربوا في افغانستان ولعل ذلك ما جعلهم هدفا مستمراً للولايات المتحدة اذ اشارت بعض المصادر الى ان

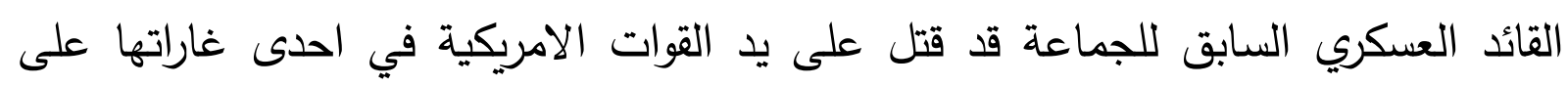
الصومال عام 2008 ، ويدعى ( ادن حاشي عيدو) والملقب بـ(ابو حسن الانصاري)(

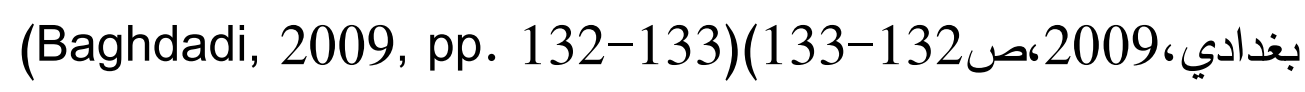
ومن أبرز اعضاء حركة شباب المجاهدين هم احمد عبدي جدوني الامين العام السابق في المحاكم الاسلامية ، وابو منصور مختار روبيو المتحدث باسم حركة شباب المجاهدين وابو يوسف صالح النبهاني ويوسف اندعدي ، و وحمد عبدو كودني الذي يعد الزعيم الحالي

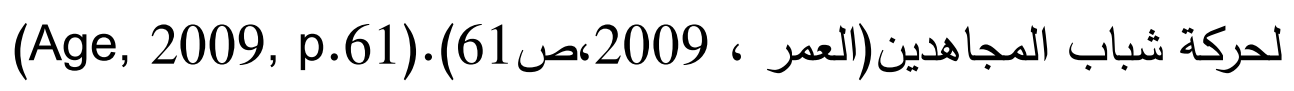

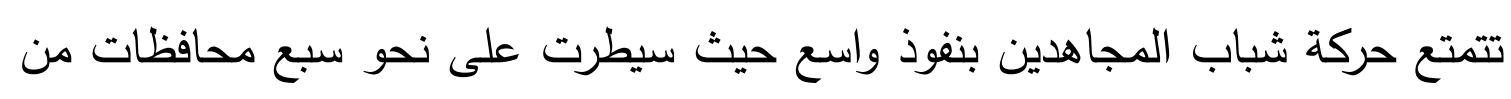
اصل ثماني عشر محافظة ، وتمتد من مشارف العاصمة مقديشو الى حدود كينيا ، فضلا 
عن انها تضم بين صفوفها عناصر تدربت في افغانستان تدريبا عاليا على عمليات (Age, 2009, p.61).الاغتيالات والتفجيرات(العمر ، 2009،صنه

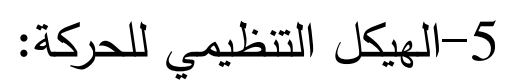
ان الهيكل التنظيمي والاداري لحركة الشباب اقرب ما يكون الى اللامركزية التنظيمية فهشاشة العلاقة بين المركز والاطراف في تفعيل المبادئ والاحكام على ارض الواقع يعكس

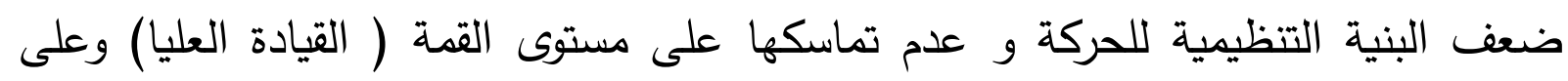
مستوى القاعدة( اتباع الحركة و القيادات الميدانية التي تباشر المهام العسكرية والامنية)

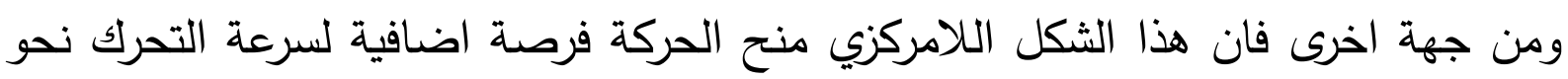
الهدف او الاستجابة والرد المباشر في حالة الشعور بالخطر وهو ما جعل الحركة تتمدد بمساحات شاسعة من الصومال خلال فترة زمنية وجيزة. كما يوجد شكل تتظيمي مطروح على مستوى النخب الفكرية للحركة وهو تكوين وتطوير بعض الاجهزة الادارية ولكن.

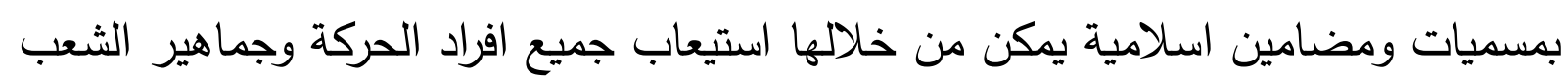

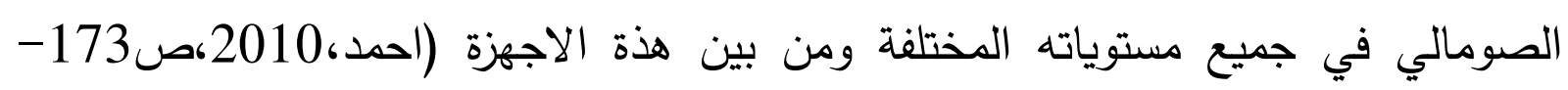
) (Ahmad, 2010, p. 173-p. 175):-175

1-جيش العسرة :-وهو الجانب العسكري والجهادي للحركة الذي يقوم بتتفيذ العمليات

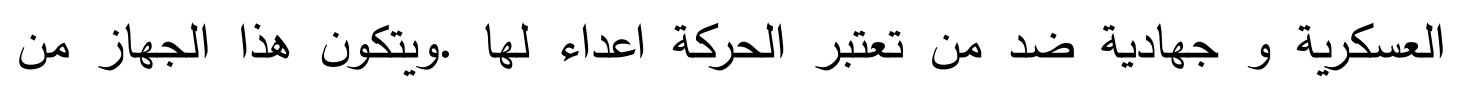

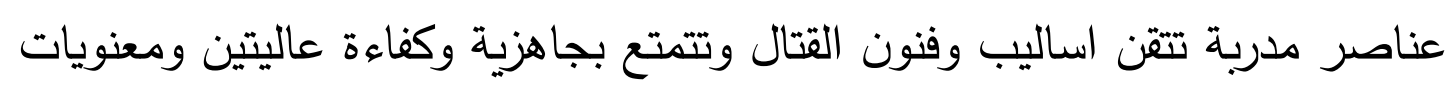
رفيعة تنطلق من عقيدة عسكرية وقتالية ثابتة هي تحقيق احدى الحسنيين (النصر

$$
\text { او الشهادة ). }
$$

r-الفرق الامنية :-هي وحدات خاصة تم تدريبها بتنفيذ العمليات الانتحارية والاغتيالات

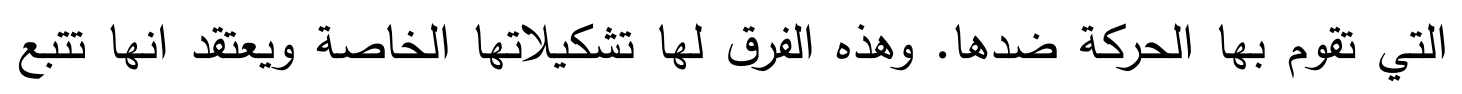

$$
\text { مباشرة لامير الحرك. }
$$

3-جيش الحسبة:- وهو يشكل الجانب الثاني للحركة الذي يوفر بعض الخدمات

$$
\text { الثانوية للمجتمع كمحاربة قطاع الطرق وغيرها }
$$


4- المؤسسة الاعلامية:- وهي من اهم ركائز عمل الحركة بجانب المال والسلاح وتتقل هذه المؤسسة الاعلامية عمليات الحركة وموقفها من الاحداث السياسية والعسكرية الجاريه من خلال الوسائط الاعلامية سواء تلك التي تمتلكها الحركة او عبر اوساط اعلامية اخرى وكانت اهم الوسائل والوسائط الاعلامية التي تستخدمها الحركة في نقل الاحداث والافكار الى الراي العام المحلي والدولي هي الة (الانترنت) التي توظفها بكفاءة ملحوظة لنقل الاخبار والعمليات العسكرية سواء بشكل مقروء

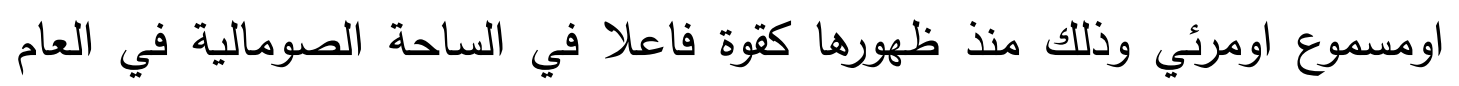
.2006 6- مملياتها العسكرية: لغرض اعطاء تصور عن قوة الحركة نعرض بعض من معاركها( بغدادي (Baghdadi, 2010, p.65):-(6502010، 1-قيام الحركة بهجوم على المجمع الرئاسي في قلب العاصمه مقديشو بقذائف الهاون

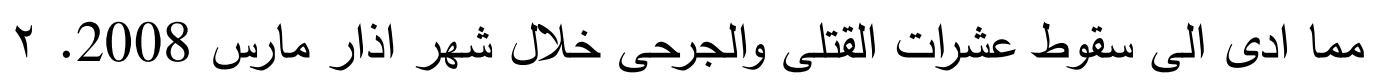
2- يتهم الرئيس الصومالي شيخ شريف شيخ أحمد حركة الشباب بالوقوف وراء تفجير انتحاري استهدف حفل لتوزيع الشهادات على الطلاب في مقديشو مما ادى الى قتل اكثر من 19 شخصا بينهم ثلاثة وزراء من الحكومة الصومالية لكن حركة نفت للك. 3-قيام الحركة بشن هجوم يومي 22 و 23 ايار مايو 2010 باتجاه القصر الرئاسي(

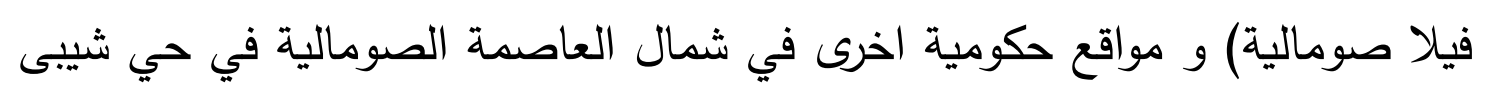
وبوند ديري وقد استخدمت الحركة في هذا الهجوم الاسلحة الثقيلة والهاونات والمدفعية المضادة للطيران والرشاشات الثثيلة وقال الناطق باسم حركة الثباب الثيخ علي محمود راجع( ان مقاتلينا هاجموا مناطق عدة يسيطر عليها جنود الحكومة الكافرة

$$
\text { قتلنا عشرات الاعداء و استولينا على مراكزهم ليلا). }
$$

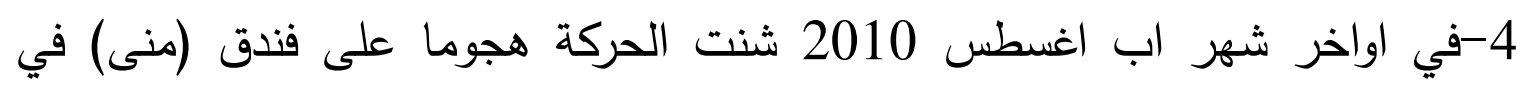
مقديشو فاردت 32 قتيلا من بينهم ستة من نواب البرلمان ثم قام احد مقاتلي الحركة بتفجير نفسه داخل الفندق وياتي هذا الحادث في اليوم الثاني من هجوم واسع 
النطاق شنته الحركة على القوات الحكومية الصومالية وقوات الاتحاد الافريقي .وقد قتل اربعة جنود اوغنديين من القوة الافريقية العاملة في الصومال خلال معارك مع حركة الثباب التي تقدمت باتجاه البرلمان في مقديشو

5-خلال شهر ايلول سبتمبر 2010 ادت المعارك الدائرة بين حركة الشباب الاسلامية والقوات الحكومية التي تساندها قوات الاتحاد الافريقي الى سقوط 230 قتيلا من المدنيين واكثر من 400 جريح في عاصمة مقديشو. 6- لم تكتفي حركة شباب المجاهدين في القيام بعمليات قتالية كبيرة ومؤثرة داخل

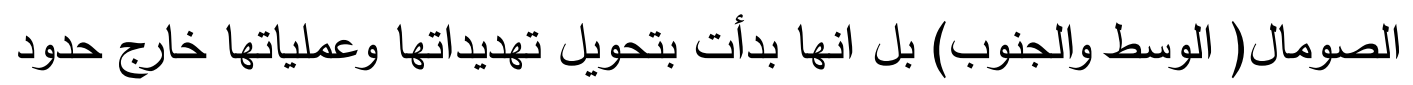

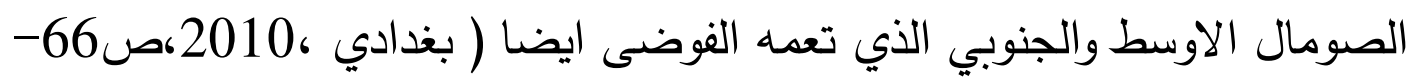
(Baghdadi, 2010, pp. 66-68).(68 7- قامت الحركة بحوالي 15 عملية إرهابية خلال شهر كانون الثاني/ يناير 2019م

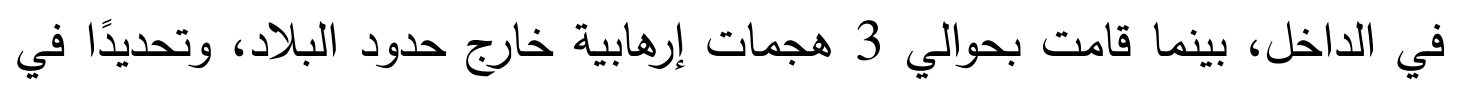
دولة كينيا.

ففي الداخل استولت حركة شباب المجاهدين على بعض العربات المدرعة بعد قتال مع

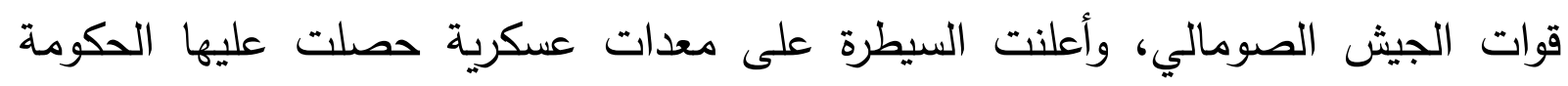
الصومالية من دول أجنبية. كما نصَب مقاتلو الحركة كمينًا للقوات الجيبوتية التابعة لبعثة الاتحاد الإفريقي في منطقة "فيدو" التي تقع على بعد 50 كيلو مترًا من منطقة "جوهر" دائه عاصمة ولاية "هيرشبيلي"، مما أدَّى إلى وقوع خسائر في الطرفين.

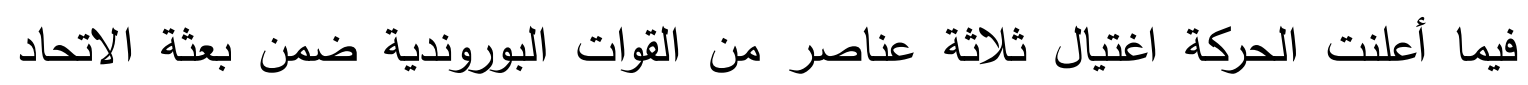
الإفريقي في الصومال في منطقة "بورني" في إقليم "ثبيلي الوسطى" شمال العاصمة مقديشو. فضلا عن اغتيال الحركة ضابطين من المخابرات الصومالية في مقديشو حسب ادعائها. معدون

وقامت حركة شباب المجاهدين بهجوم ضد قافلة من القوات الإثيوبية ضمن بعثة "أميصوم"، أسفر القتال عن خسائر كبيرة في صفوف الطرفين، وتم تدمير سبع شاحنات تابعة للقوات الإثيوبية، وهو ما أثار استياء الجانب الإثيوبي وأعلنت على إثره أديس أبابا 
استعدادها لشَنّ هجوم شامل على مقاتلي الحركة كردّ فعلٍ، حيث أعلنت وزارة الدفاع

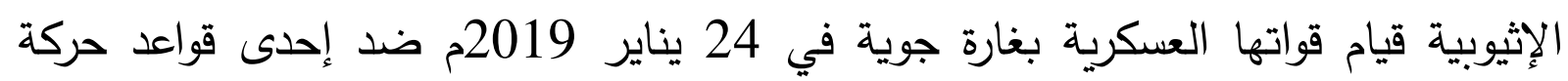
الشباب في ولاية جنوب غرب الصومال؛ ردًّا على استهداف الحركة للقافلة (عسكر،2019: (Askar, 2019: https://www.qiraatafrican.com/home/new) https://www.qiraatafrican.com/home/new) 7-اسباب تصعيد عمليات حركة شباب المجاهدين:

ثمة عدد من الدوافع والأسباب التي دفَعت حركة شباب المجاهدين إلى تصعيد عملياتها في الاخل الصومالي، وفي الجوار الإقليمي خلال المدة الأخيرة، تتمثل أبرزها في (عسكر،2019، : 2019: https://www.qiraatafrican.com/home/new):1-الانتقام من القوَات الحكومية: حيث قامت قوَّات من الجيش الصومالي في بدايات كانون الثاني /يناير 2019م بإعدام سبعة من عناصر الحركة في إقليم غدو في جنوب غرب الصومال؛ تنفيذًا لتعليمات من قيادة الجيش الصومالي ووزارة الدفاع الصومالية، بعد اعترافه بقتل 14 شخصًا في مدينة "بارديري"، وأشار أحد القادة إلى تلى فئل

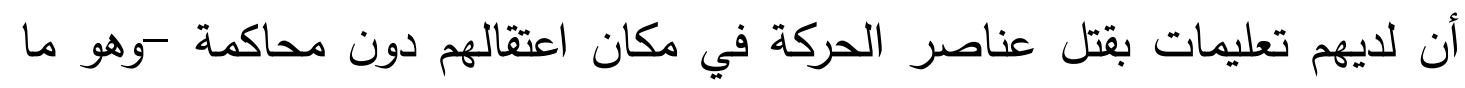
نفته قيادات من الجيش في وقت لاحق-، الأمر الذي دفَع الحركة إلى تكثيف عملياتها ضد القوات الحكومية في مناطق مختلفة؛ بهدف الانتقام. 2-ََفت الأنظار عن الانشقاقات بداخلها: ففي الوقت الذي تشهد فيه الحركة انشقاقات

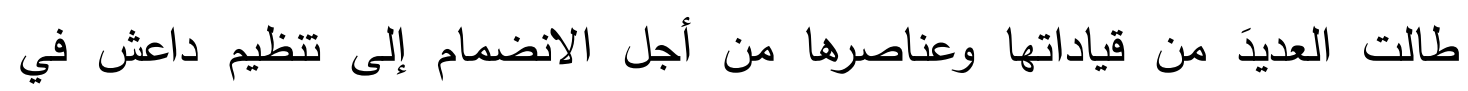
الصومال؛ بما أدَّى إلى بدء الصراع بينهما، توسع الحركة من عملياتها الإرهابية في أنحاء الصومال وفي بعض دول الجوار؛ من أجل تحقيق مكاسب يتم بها تغطية ما يجري في داخلها. 3- قرب انتخابات الرئاسة 2020م: تسعى الحركة إلى إضعاف موقف الحكومة

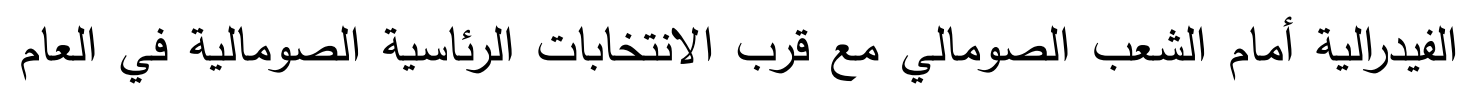

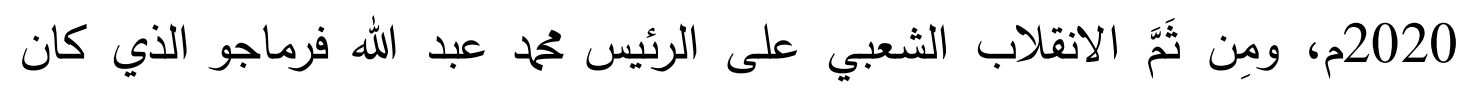


القضاء على الحركة ضمن أهمّ أولوياته عند صعوده إلى السلطة ولم ينجح فيه،

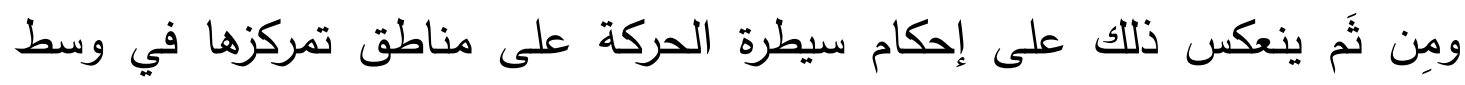
وجنوب البلاد من جهة، واجتذاب عناصر جديدة من الثباب الصومالي ضمن صفوفها من جهة أخرى.

4- تأكيد التفوق والزعامة في المنطقة: ويتعلق الأمر بالصراع القائم في قارة إفريقيا بين تنظيمي القاعدة التي بايعتها الحركة، وتنظيم داعش من خلال تصعيد عملياتها في الداخل والخارج، وتهديد الأمن القومي لدول الجوار الإقليمي، وتحقيق التفوق على لتى دائي تنظيم داعش في ظل تتامي الصراع بينهما؛ من أجل توطيد النفوذ في الصومال.

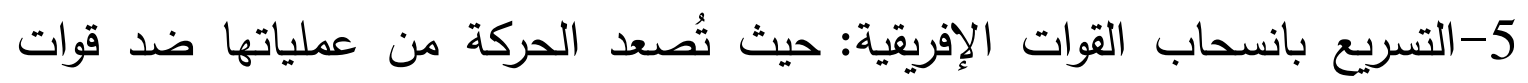
الدول الإفريقية في بعثة "أميصوم"؛ بهدف إرسال تحذير قويّ لها إلى جانب بقية الدول الإفريقية بشأن تسريع انسحاب قواتها من الصومال، وعدم إرسال قوات جديدة. فضلًا عن استهداف الحركة الأراضي الكينية بعمليات إرهابيَّة ردا على قيام قوات إتهات كينية بعبور الحدود إلى الصومال، وتدمير مقرات تابعة لشركة "هرمود" الصومالية للمرة الثامنة، مما تسبَّب في خسائر مادية وبشرية وأثر سلبًا على سكان إقليمي غدو فئي

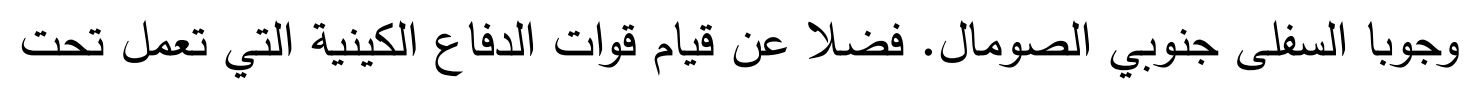
قيادة بعثة الاتحاد الإفريقي بقتل سبعة من مقاتلي الحركة في جنوب الصومال. 6-الحد من القوى الإقليمية والدولية في المنطقة: من خلال تهديد مصالحها الحيوية، سواء في الصومال أو في المنطقة، في ظل اعتبار التواجد الإقليمي والدولي بمثابة احتلال وغزو للمنطقة، والذي ترفضه الحركة، كما تتنقد ما تسميه تواطؤ الحكومة الصومالية بإقامة علاقات مع تلك القوى. 7-إفساد التطورات الإيجابيَّة في منطقة القرن الإفريقي: حيث تسعى الحركة إلى محاولة خَلْق الفوضى في المنطقة؛ من أجل تعطيل أية جهود تقدمية بهدف التكامل السياسي والاقتصادي في القرن الإفريقي، خاصة في أعقاب نجاح المصالحة

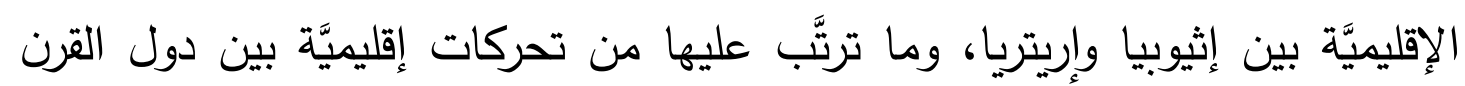

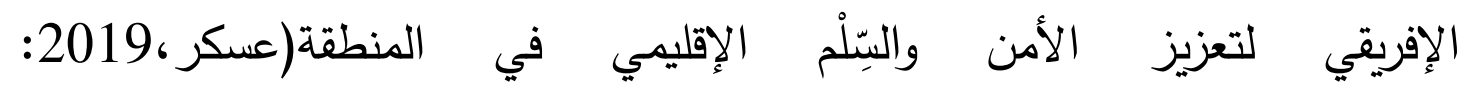


(Askar, 2019: https://www.qiraatafrican.com/home/new) https://www.qiraatafrican.com/home/new). 8-الصراع داخل حركة الثباب : شهدت الحركة حالة من الصراع الدامي بينها وبين عناصر موالية لتنظيم داعش واخرى موالية لتتظيم القاعدة ،حدث ذلك الصراع عندما قام الثيخ عبدالقادر مؤمن موهو من أهمّ منظري الفكر الجهادي في الصـومال وعضـو حركـة الشباب- في تسـيل صـوتي تداولـه

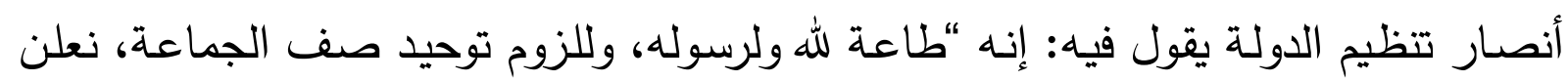
نحن مجموعة من مجاهدي الصومال بيعتتا للخليفة إبراهيم بن عواد الحسيني القريشي (أبي لهي

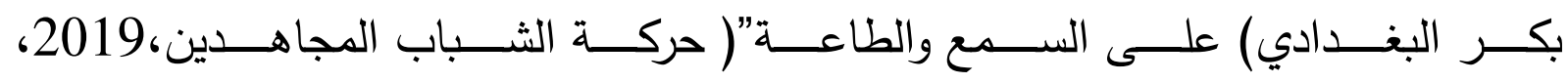
) https://rouyaturkiyyah.com/research-articles-and-commentaries (Harakat al-Shabab al-Mujahideen, 2019, https://rouyaturkiyyah.com/research-articles-and-commentaries) فضلا عن ذلك؛ قام الشيخ حسَّان حسين المنظّر الجهادي المقيم في العاصمة الكينية نيروبي وعددُ من الدعاة والكوادر برمي ثقلهم لضم بعض العناصر من الثباب إلى (تنظيم

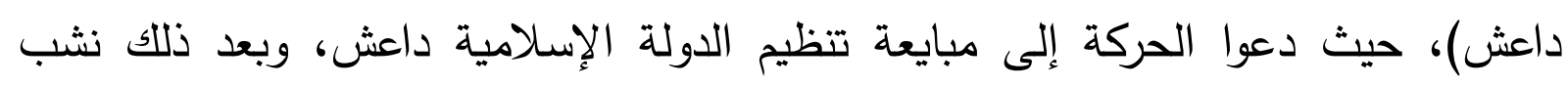

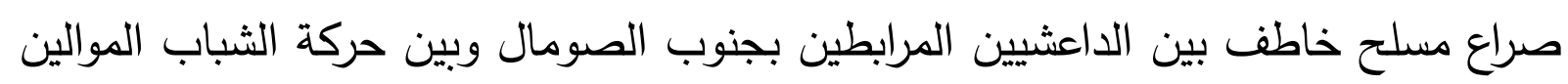
للقاعدة في قرى بمحافظة جوبا الوسطى بجنوب الصومال، ولقلة عدد الداعشيين كانت الغلبة للقاعديّين (الحركة الأم)، وهرب الداعشيون إلى الأدغال في المحافظة. إنّ الصراع الحالي بين داعش والحركة في الصومال صراع نفوذ إداري وسياسي وميداني

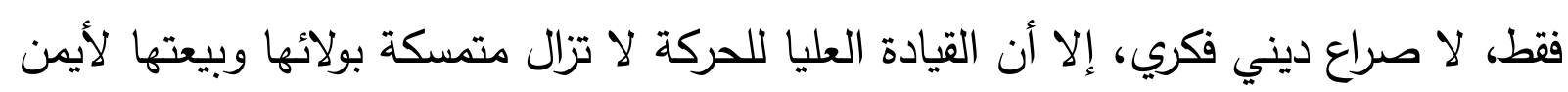
الظواهري, والأمر الثاني هو ارتباط حركة الشباب بالقاعدة في اليمن، وهي علاقة عضوية الانية

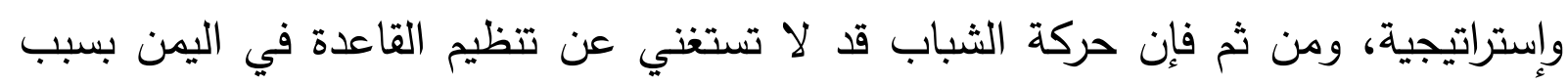
حصولها على معونات عدة. يبدو أن هناك مجموعة من المبررات والدوافع التي ساهمت في انتشار داعش في

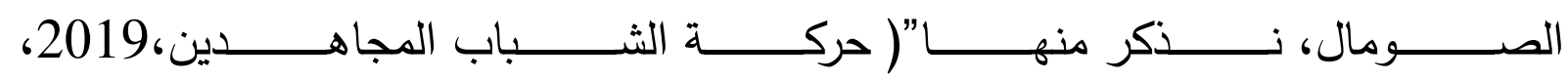


) https://rouyaturkiyyah.com/research-articles-and-commentaries (Harakat al-Shabab al-Mujahideen, 2019,

https://rouyaturkiyyah.com/research-articles-and-commentaries:1-الانتشار السريع للخلافة وتوسعها على مستوى العالم ،جعل العديد من الشباب يفكر

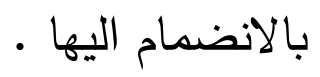
2- النجاحات والانتصارات التي حققها تنظيم داعش على المستوى العسكري فضلا عن انتشارها السريع في عدة دول اوربية وافريقية واسيوية وتمكنها من ضرب عدة اهداف في العديد من دول العالم. 3-انسحاب حركة شباب المجاهدين من العاصمة مقديشو وتراجعها ميدانيا فضلا عن

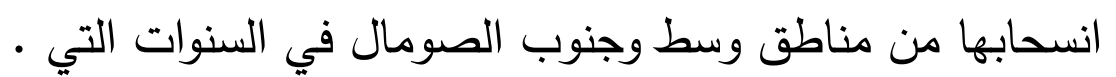
4-تمكن القوات الافريقية من السيطرة على المدن الساحلية فضلا عن سيطرتها على وهلى الموانئ وتحديدا كيسمايو وبراوي ومركا الى جانب ضعف الامكانيات المادية للحركة.

ولعل ذلك ما يجعل بعض انصار الحركة يفكر بالانضمام الى تتظيم داعش الامر الذي

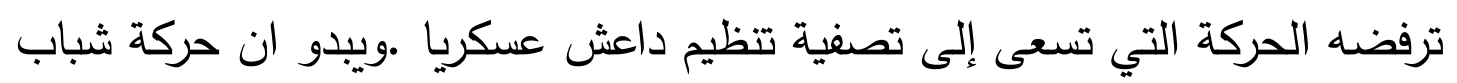

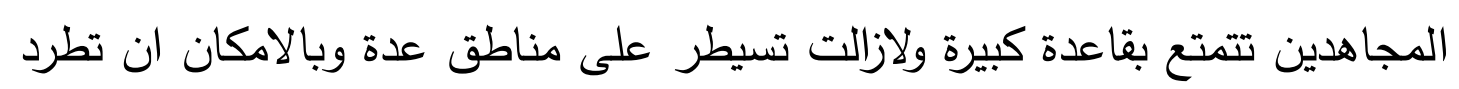

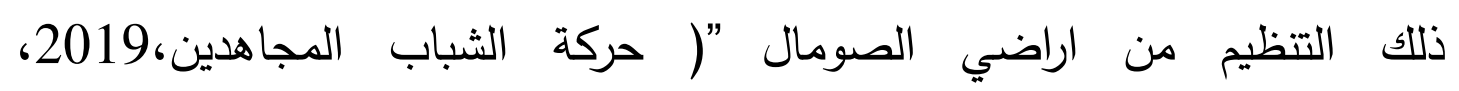
https://rouyaturkiyyah.com/research-articles-and-

) (Harakat al-Shabab al-Mujahideen, 2019, commentaries https://rouyaturkiyyah.com/research-articles-andcommentaries) 


\section{الخاتمة}

كانت وما تزال حركة شباب المجاهدين الصومالية من الحركات التي تمارس دورها الفاعل في الساحة الصومالية ،لاسيما انها من الحركات التي فرضت سيطرتها على مساحات شاسعة من اراضي الصومال ،واستطاعت ان تفرض الضرائب على عامة الناس تحت ذريعة الزكاة ،ليس هذا فحسب بل انها اخذت تشتري مساحات شاسعة من الاراضي الزراعية وبارخص الاثمان .وحاولت ان تكسب اكبر عدد من الشباب الصوماليين من اجل

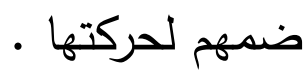
وفي ظل الهجمات المستمرة التي تقوم بها الحركة فان الاوضاع السياسية والامنية في الصومال تشهد تدهور كبيرفي ظل النقص الحاصل لدى الدولة من حيث الفرق العسكرية قياسا لمساحة الدولة ،فضلا عن نقص التسلح والقصور الحاصل في عملية تدريب الفرق العسكرية الصومالية. ولعل ما يشجع حركة شباب المجاهدين على التوسع والانتشار قيام بعض القبائل بتقديم الدعم والاسناد لتلك الحركة،وهذا ما يعرقل مسار عملية المصالحة الوطنية في الصومال

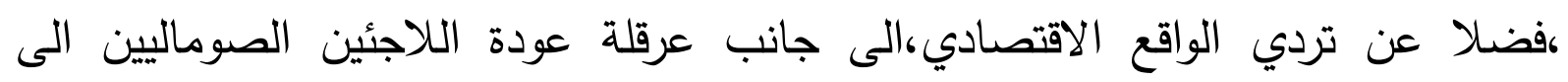
اراضيهم.

ومن اجل الحيلولة دون تفاقم الوضع في الصومال والحد من انتشار الحركات المسلحة

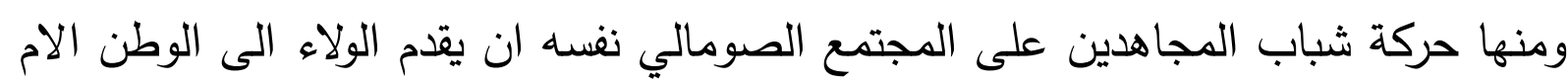
(ارض الصومال)،وان تعمل القبائل الصومالية على تقديم الدعم الكامل للحكومة الصومالية

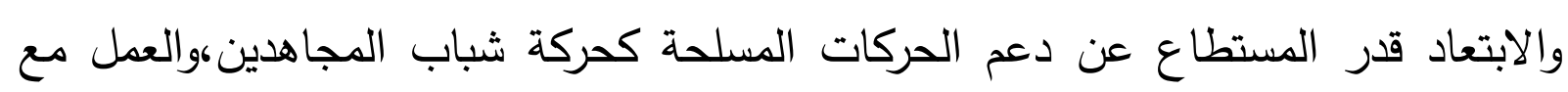
دول الجوار على ضبط الحدود للحيلولة دون تدفق تلك الحركات الى ارض الصومال. الى جانب ذلك فعلى القوى الدولية ومنها الولايات المتحدة الامريكية ان تقدم الدعم اللازم للحكومة الصومالية،سواء في مجال تقديم الاغاثات والمساعدات الى الشعب

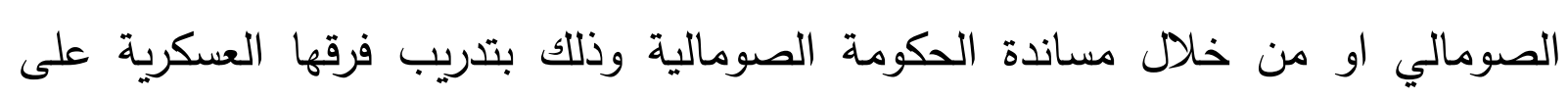
استخدام الاسلحة والمعدات العسكرية المتطورة فضلا عن دعم الحكومة الصومالية اقتصاديا،وذلك من خلال محاربة الفساد المستشري في الصومال والذي اوصل الصوماليين 
الى حد المجاعة.وبالتالي فان تقديم تلك الحلول تجعل بالامكان الحد من انتشار التتظيمات

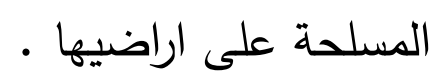

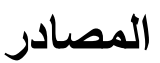

• بغدادي ،عبد السلام ابراهيم 2010،حركة شباب المجاهدين الصومالية،سلسلة دراسات استراتيجية،جامعة بغداد،مركز الدراسات الاستراتيجية والدولية،العدد 107. • بغدادي،عبد السلام إبراهيم، 2009 ،الصراع الداخلي في الصومال والتخخلات الخارجية

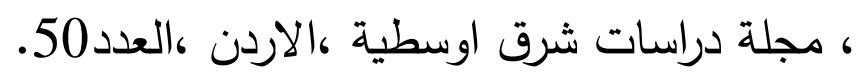
• حافظ ،صلاح الدين ،1982، صراع القوى العظىى حول القرن الإفريقي،الكويت ، سلسلة عالم المعرفة. ه الضمور ،جمال حمود ،2004،مشروعية الجزاءات الدولية والتدخل الدولي ضد ليبيا والسودان والصومال،عمان،مركز القدس للدراسات السياسية. عبيد كمنى حسين ،2007،منظمة الايقاد ودورها في مواجهة النزاعات الافريقية (مشكلتي جنوب السودان والصومال انموذجا)،سلسلة دراسات استراتيجية ،جامعة بغداد،مركز الدراسات الاستراتيجية،العدد92. • المديني، توفيق ،2012،تاربخ الصراعات السياسية في السودان والصومال،وزارة الثقافة ،منشورات الهيئة العامة السورية للكتاب،دمشق. محمد ،علي حسين ، د.ت ،الازمة الصومالية :اسبابها وطبيعتها ونتائجها، سلسلة دراسات استراتيجية ، العدد 90. موسى ،عايدة العزب ،2009،محنة الصومال من التفتيت الى القرصنة،القاهرة ،مكتبة الشرق الدولية. حميد ،خميس دهام 1996،الصومال دراسة في مشكلات توحيد الصومال الكبير والوحدة الوطنية والتدخل الدولي ، رسالة ماجستير غير منشورة ، جامعة بغداد،كلية العلوم السياسية. 
• خميس ،خلود حمح ،1998،سياسة اثيوبيا الاقليمية المعاصرة تجاه دول الجوار الجغرافي العربي، رسالة ماجستير (غير منشورة) ، جامعة بغداد ،كلية العلوم السياسية . • احمد ،محمد بخاري ، 2010،المعارضة الاسلامية في الصومال:قرأة في بنيتها التتظيمية وصراعاتها مع حكومة الوحدة الوطنية،مجلة الثاهد،القاهرةهركز الثاهد للبحوث والدراسات الاعلامية،العدد الاول.

• رأفت ،اجلال 1993،الازمة الصومالية،مجلة المستقبل العربي،بيروت،العدد 173. •العمر ،ناصر بن سليمان ،2009،رؤية اصلاحية للمشكلة الصومالية،مجلة البيان

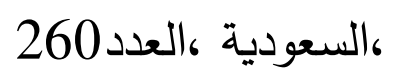
منير ،احمد ،1989،هل الحق على الطليان في مجزرة عيد الاضحى ، مجلة كل

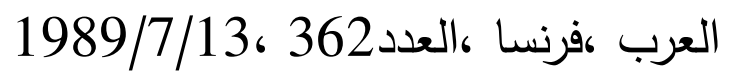
محمود، احمد ابراهيم ،تجربة التذخل الدولي في الصومال وراوندا،مجلة السياسة الدولية،القاهرة،العدد122،حزيران 1990، 1980. 1920. •بري ،محمد سياد،1989،الصعود الى الهاوية،هجلة الأسبوع العربي ،لبنان، العدد العدئ .15760 • صحيفة الحياة ، القاهرة، العدد 2002 م 14218 ، 21شباط • صحيفة الرأي ،الاردن ، العدد 7778 ، 9 ،تشرين الثاني 1991 ،

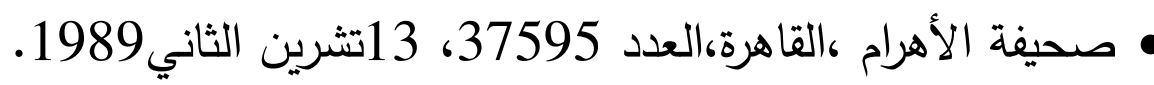

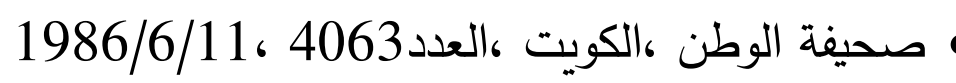
• الحليم ،اميرة محمد عبد ،2020،حركة الشباب الصومالية والتحديات،نقلا عن شبكة https://www.imctc.org/Arabic/ArticleDetail/Inde الانترنت الموقع: • حكومة،2009، الصومال 7رؤساء و 11 رئيس وزراء و 37حكومة، نقلا عن الانترنت ، الموقع

http://wwwislamonline.net/ar/page.p1. 
• عسكر ،احمد 2019،لماذا تصعد حركة شباب المجاهدين عملياتها في منطقة القرن

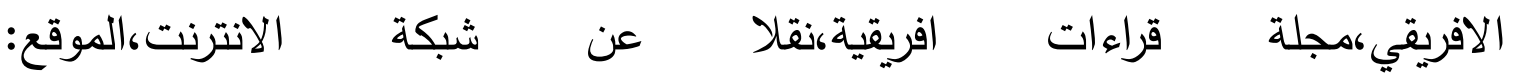
https://www.qiraatafrican.com/home/new/ ه المجهول ،2010،الواقع الصومالي المتأزم :بين تفاقم الازمة وجهود المصالحة والمستقبل ،نقلا عن شبكة الانترنت الموقع: http://www.aljazeera.net.p6.

المستقبلية ،2019،حركة الشباب المجاهدين في الصومال نشأتها وواقعها ومساراتها ،رؤية تركية:دورية محكمة في الثؤون التركية والدولية،قلا عن شبكة الانترنت الموقع: https://rouyaturkiyyah.com/research-articles-and-commentaries /

\section{References}

- Baghdadi, Abdul Salam Ibrahim, 2010, Somali Mujahideen Youth Movement, Strategic Studies Series, University of Baghdad, Center for Strategic and International Studies, No. 107.

- Baghdadi, Abd al-Salam Ibrahim, 2009, The Internal Conflict in Somalia and External Interventions, Journal of Middle Eastern Studies, Jordan, Issue 50.

- Hafez, Saladin, 1982, The Great Power Struggle over the Horn of Africa, Kuwait, The World of Knowledge Series.

- Damour, Jamal Hammoud, 2004, the legality of international sanctions and international intervention against Libya, Sudan, and Somalia, Amman, Al-Quds Center for Political Studies.

- Obaid, Mona Hussein, 2007, IGAD Organization and its Role in Confronting African Conflicts (The Problems of South Sudan 
and Somalia as a Model), Strategic Studies Series, University of Baghdad, Center for Strategic Studies, Issue 92.

- Al-Madani, Tawfiq, 2012, History of Political Conflicts in Sudan and Somalia, Ministry of Culture, Publications of the Syrian General Book Authority, Damascus.

- Muhammad, Ali Hussein, D.T, The Somali Crisis: Its Causes, Nature and Results, Strategic Studies Series, No. 90.

- Musa, Aida Al-Azab, 2009, The plight of Somalia from fragmentation to piracy, Cairo, Al Sharq International Library.

- Hamid, Khamis Daham, 1996, Somalia: Study on problems of the unification of Greater Somalia, national unity and international intervention, unpublished MA thesis, University of Baghdad, College of Political Sciences.

- Khamis, Khulud Muhammad, 1998, Ethiopia's Contemporary Regional Policy towards the Arab Geographical Neighboring Countries, Master Thesis (unpublished), University of Baghdad, College of Political Science.

- Ahmed, Muhammad Bukhari, 2010, The Islamic Opposition in Somalia: Reading in its Organizational Structure and Conflicts with the National Unity Government, Al-Shahid Magazine, Cairo, Al-Shahid Center for Research and Media Studies, Issue 1 .

- Raafat, ljlal, 1993, the Somali Crisis, Arab Future Magazine, Beirut, Issue 173. 
- Al-Omar, Nasser bin Suleiman, 2009, A Reform Vision for the Somali Problem, Al-Bayan Magazine, Saudi Arabia, Issue 260

- Mounir, Ahmed, 1989, Is the Right Over the Italians in the Massacre of Eid Al-Adha, Kul Al Arab Magazine, France, Issue $362,7 / 13 / 1989$

- Mahmoud, Ahmed Ibrahim, The Experience of International Intervention in Somalia and Rwanda, Al Siyasa Al Dawlia Journal, Cairo, Issue 122, June 1990.

- Berri, Muhammad Siyad, 1989, Ascending to the Abyss, Arab Week Magazine, Lebanon, Issue 15760.

- Al-Hayat Newspaper, Cairo, No. 14218, February 21, 2002

- 2-Al-Rai Newspaper, Jordan, No. 7778, November 9, 1991

- Al-Ahram Newspaper, Cairo, No. 37595, November 13, 1989.

- 4-Al-Watan Newspaper, Kuwait, No. 4063, 6/11/1986

- Al-Halim, Amira Muhammad Abd, 2020, The Somali Youth Movement and Challenges, quoted from the Internet. Website: https://www.imctc.org/Arabic/ArticleDetail/Inde

- Askar, Ahmad, 2019, Why is the Mujahideen Youth Movement stepping up its operations in the Horn of Africa, Qiraat Afriqiyah magazine, citing the internet, website: https://www.qiraatafrican.com/home/new/

- The Unknown, 2010, The Tense Somali Reality: Between the Exacerbation of the Crisis, the Efforts of Reconciliation and the Future, Quoted from the Internet.http: //www.aljazeera.net.p6. 
- Future, 2019, The Young Mujahideen Movement in Somalia, its origins, reality and paths, Turkish vision: a refereed journal in Turkish and international affairs, quoted from the internet website: https://rouyaturkiyyah.com/research-articles-andcommentaries/ 